Article

\title{
Synthesis and Evaluation of New Pyrazoline Derivatives as Potential Anticancer Agents
}

\section{Muhammed Karabacak ${ }^{1, \dagger}$, Mehlika Dilek Altıntop ${ }^{1, \dagger}$, Halil İbrahim Çiftçi ${ }^{2, \dagger}$, Ryoko Koga ${ }^{2}$, Masami Otsuka ${ }^{2}$, Mikako Fujita ${ }^{3}$ and Ahmet Özdemir ${ }^{1, *}$}

1 Department of Pharmaceutical Chemistry, Faculty of Pharmacy, Anadolu University, Eskişehir 26470, Turkey; E-Mails: rem1596@hotmail.com (M.K.); mdaltintop@anadolu.edu.tr (M.D.A.)

2 Department of Bioorganic Medicinal Chemistry, School of Pharmacy, Kumamoto University, Kumamoto 862-0973, Japan; E-Mails: 130y2011@st.kumamoto-u.ac.jp (H.İ.Ç.); kk1205@kumamoto-u.ac.jp (R.K.); motsuka@gpo.kumamoto-u.ac.jp (M.O.)

3 Research Institute for Drug Discovery, School of Pharmacy, Kumamoto University, Kumamoto 862-0973, Japan; E-Mail: mfujita@kumamoto-u.ac.jp

$\dagger$ These authors contributed equally to this work.

* Author to whom correspondence should be addressed; E-Mail: ahmetefegunes@gmail.com; Tel.: +90-222-3350580 (ext. 3753); Fax: +90-222-3350750.

Academic Editor: Jean Jacques Vanden Eynde

Received: 17 August 2015 / Accepted: 14 October 2015 / Published: 20 October 2015

\begin{abstract}
New pyrazoline derivatives were synthesized and evaluated for their cytotoxic effects on AsPC-1 human pancreatic adenocarcinoma, U87 and U251 human glioblastoma cell lines. 1-[((5-(4-Methylphenyl)-1,3,4-oxadiazol-2-yl)thio)acetyl]-3-(2-thienyl)-5-(4-chlorophenyl)2-pyrazoline (11) was found to be the most effective anticancer agent against AsPC-1 and U251 cell lines, with $\mathrm{IC}_{50}$ values of $16.8 \mu \mathrm{M}$ and $11.9 \mu \mathrm{M}$, respectively. Tumor selectivity of compound 11 was clearly seen between Jurkat human leukemic T-cell line and human peripheral blood mononuclear cells (PBMC). Due to its promising anticancer activity, compound 11 was chosen for apoptosis/necrosis evaluation and DNA-cleavage analysis in U251 cells. Compound 11-treated U251 cells exhibited apoptotic phenotype at low concentration $(1.5 \mu \mathrm{M})$. DNA-cleaving efficiency of this ligand was more significant than cisplatin and was clearly enhanced by $\mathrm{Fe}(\mathrm{II})-\mathrm{H}_{2} \mathrm{O}_{2}$-ascorbic acid systems. This result pointed out the relationship between the DNA cleavage and the cell death.
\end{abstract}


Keywords: pyrazoline; oxadiazole; anticancer activity; apoptosis; DNA cleavage

\section{Introduction}

Cancer is not a single disease, but a large group of diseases characterized by uncontrolled, rapid, and pathological proliferation of abnormally transformed cells. Despite recent advances in cancer therapy, cancer is still the second leading cause of death after cardiovascular disorders throughout the world [1-4].

Resistance to chemotherapeutic agents remains a key challenge in the fight against cancer. Another challenge for chemotherapy is lack of selectivity. Generally anticancer drugs destroy normal cells as well as cancer cells and often cause serious adverse effects. Therefore, new antineoplastic agents are continually under development to selectively destroy tumour cells or at least limit their proliferation [1-4].

Diversely substituted pyrazolines embedded with a variety of functional groups are found in many important biologically-active compounds and considerable research on this class of agents has been carried out. They exhibit a wide spectrum of biological activities such as antimicrobial, anti-inflammatory, antidepressant, and anticancer effects. Among the reported activities, it is important to note that pyrazolines are not only useful in treatment of various cancer types, including brain, bone, mouth, esophagus, stomach, liver, bladder, pancreas, cervix, lung, breast, colon, rectum, and prostate cancers, but also some of them act as cancer chemopreventive agents [5-23]. In many studies, pyrazoline derivatives were reported as epidermal growth factor receptor tyrosine kinase (EGFR-TK) inhibitors [19], aurora kinase inhibitors [20], COX-2/B-Raf inhibitors [21], telomerase inhibitors [22], tubulin assembling inhibitors [23]. Additionally, 1,3,4-oxadiazole has emerged as an important scaffold owing to its metabolic profile and ability to engage in hydrogen bonding with receptor site. Recent studies have indicated that 1,3,4-oxadiazole derivatives exhibit potent anticancer activity against different cancer cell lines through the inhibition of different growth factors, enzymes and kinases including telomerase, histone deacetylase (HDAC), methionine aminopeptidase (MetAP), thymidylate synthase (TS), glycogen synthase kinase-3 (GSK), epidermal growth factor (EGF), vascular endothelial growth factor (VEGF), and focal adhesion kinase (FAK) [24-26]. Triazoles [27], tetrazoles [28], thiadiazoles [29], and pyrimidines [4] have also been reported to show anticancer activity.

Prompted by the aforementioned findings and in the continuation of our ongoing research in the field of design, synthesis, and biological evaluation of pyrazoline derivatives [30-35], herein we described the synthesis and evaluation of a new series of heteroaryl substituted pyrazolines as potential anticancer agents against AsPC-1 human pancreatic adenocarcinoma and two glioblastoma cell lines, U87 and U251 cell lines. Furthermore, tumor selectivity test on blood cells (PBMC and Jurkat cells) and the apoptotic, necrotic, and DNA-cleavage analysis against U251 cells were carried out using the most effective compound.

\section{Results and Discussion}

The synthesis of new pyrazoline derivatives (1-12) was carried out according to the steps shown in Scheme 1. In the initial step, 1-(2-thienyl)-3-(4-chlorophenyl)-2-propen-1-one was synthesized via the base-catalyzed Claisen-Schmidt condensation of 2-acetylthiophene with 4-chlorobenzaldehyde. The ring closure reaction of the chalcone with hydrazine hydrate afforded 5-(4-chlorophenyl)-3-(2-thienyl)- 
2-pyrazoline. 1-(Chloroacetyl)-3-(2-thienyl)-5-(4-chlorophenyl)-2-pyrazoline was obtained by the reaction of 5-(4-chlorophenyl)-3-(2-thienyl)-2-pyrazoline with chloroacetyl chloride in the presence of triethylamine. The reaction of 1-(chloroacetyl)-3-(2-thienyl)-5-(4-chlorophenyl)-2-pyrazoline with aryl thiols afforded 1-[(aryl)thioacetyl]-3-(2-thienyl)-5-(4-chlorophenyl)-2-pyrazolines (1-12). Thus, the synthetic procedure was shown to be versatile, applicable to the preparation of many derivatives.<smiles>CC(C)(C)CCCCCCCCCC(=O)c1cccs1</smiles><smiles>O=C(CS[Ga])N1N=C(c2cccs2)CC1c1ccc(Cl)cc1</smiles>

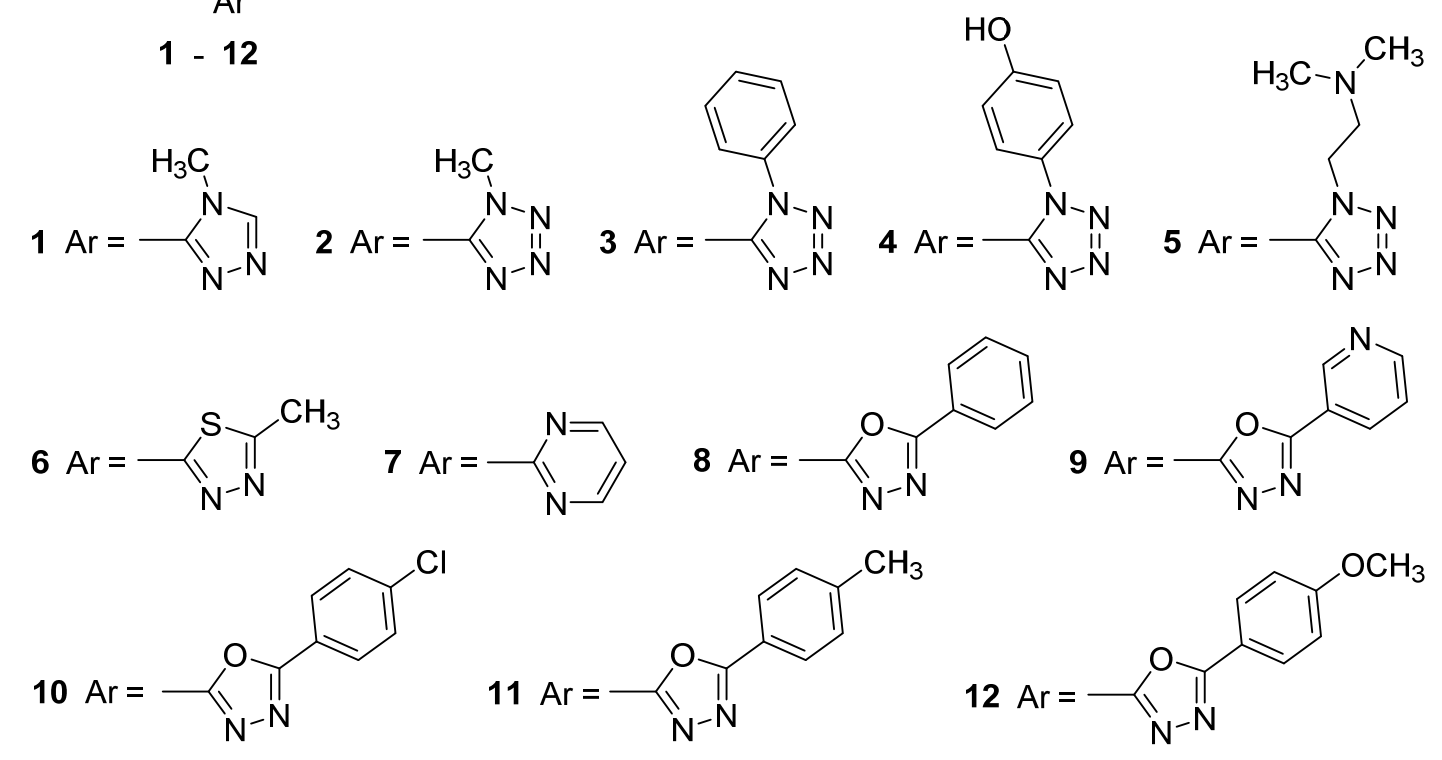

Scheme 1. The synthesis of compounds 1-12. Reagents and conditions: (i) 4-Chlorobenzaldehyde, $10 \%$ aqueous sodium hydroxide solution, ethanol, rt, 6-8 h; (ii) $80 \%$ hydrazine hydrate, ethanol, reflux, $5 \mathrm{~h}$; (iii) $\mathrm{ClCOCH}_{2} \mathrm{Cl}$, TEA, toluene, rt, $1 \mathrm{~h}$; (iv) Ar-SH, acetone, rt, $8 \mathrm{~h}$.

The structures of the compounds were elucidated by IR, ${ }^{1} \mathrm{H}-\mathrm{NMR},{ }^{13} \mathrm{C}-\mathrm{NMR}$, mass spectral data, and elemental analyses. In the IR spectra of compounds 1-12, all derivatives had a strong, characteristic band in the region $1670-1641 \mathrm{~cm}^{-1}$ due to $\mathrm{C}=\mathrm{O}$ stretching vibration. The asymmetric and symmetric stretching bands for aliphatic $\mathrm{C}-\mathrm{H}$ group occurred at $2983-2920 \mathrm{~cm}^{-1}$. The aromatic $\mathrm{C}-\mathrm{H}$ stretching vibrations gave rise to a band at $3134-3078 \mathrm{~cm}^{-1}$. The $\mathrm{C}=\mathrm{C}, \mathrm{C}=\mathrm{N}$ and $\mathrm{C}-\mathrm{N}$ stretching bands appeared in the region of 1548-1408 and 1398-1012 $\mathrm{cm}^{-1}$, respectively. 
In the ${ }^{1} \mathrm{H}-\mathrm{NMR}$ spectra of the compounds, the $\mathrm{CH}_{2}$ protons of the pyrazoline ring resonated as a pair of doublets at $\delta 3.16-3.24 \mathrm{ppm}\left(\mathrm{C}_{4}-\mathrm{H}_{\mathrm{A}}\right), 3.89-3.94 \mathrm{ppm}\left(\mathrm{C}_{4}-\mathrm{H}_{\mathrm{B}}\right)$. The $\mathrm{CH}$ proton appeared as a doublet of doublets at $\delta 5.57-5.63 \mathrm{ppm}(\mathrm{Hx})$ due to the vicinal coupling with two magnetically non-equivalent protons of the methylene group at position four of the pyrazoline ring $\left(J_{\mathrm{AB}}=17.60-18.00 \mathrm{~Hz}, J_{\mathrm{AX}}=\right.$ $4.00-4.80 \mathrm{~Hz}, J_{\mathrm{BX}}=11.20-12.00 \mathrm{~Hz}$ ). The $\mathrm{CH}_{2}$ protons of the acetyl group at position 1 of the pyrazoline ring were observed at $4.32-4.83 \mathrm{ppm}$ as a doublet $(J=15.20-16.40 \mathrm{~Hz})$. This geminal coupling resulted from the steric structure of the compound. These geminal protons were observed as a doublet due to two different possible conformations since rigid protons occurred (Figure 1). All the other aromatic and aliphatic protons were observed at expected regions.

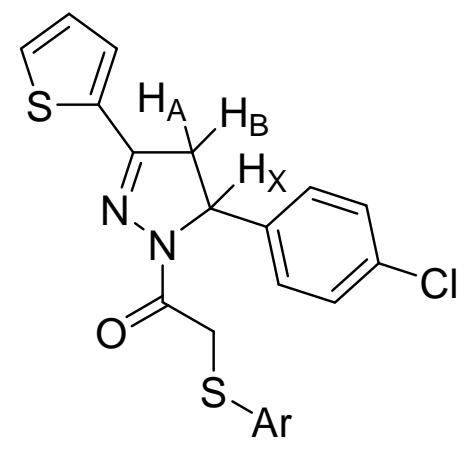

Figure 1. ABX system of the pyrazoline ring.

In the ${ }^{13} \mathrm{C}-\mathrm{NMR}$ spectra of the compounds, the signal due to the carbonyl carbon appeared at 163.92-166.37 ppm. The ${ }^{13} \mathrm{C}-\mathrm{NMR}$ chemical shift values of the carbon atoms at 43.34-43.42 ppm $\left(\mathrm{C}_{4}\right)$, 60.04-60.24 ppm $\left(\mathrm{C}_{5}\right)$ and 151.47-152.38 ppm $\left(\mathrm{C}_{3}\right)$ corroborate 2-pyrazoline character deduced from the ${ }^{1} \mathrm{H}-\mathrm{NMR}$ data. The signal due to the $\mathrm{S}-\mathrm{CH}_{2}$ carbon was observed in the region 34.30-39.72 ppm. The other aromatic and aliphatic carbons were observed at expected regions. The mass spectral data of the synthesized compounds were found in full agreement with the proposed structures. All compounds gave satisfactory elemental analysis.

The anticancer effects of new pyrazoline derivatives (1-12) and cisplatin (positive control) in the range of 10-500 $\mu \mathrm{M}$ concentrations were tested. Since only limited choice of drugs are available for pancreatic cancer and glioma, AsPC-1 human pancreatic adenocarcinoma, U87 and U251 glioblastoma cell lines were used (Figure 2). Cisplatin was chosen as a control, considering its wide use in the treatment of several types of human cancer.

Compounds 1-12 were evaluated for their cytotoxic effects on these cell lines by MTT assay (Figure 2 and Table 1), to determine their anticancer potential and selectivity. The activity of the tested compounds was influenced considerably by the nature of the aryl group. Compounds $1,10,11$, and 12 were found to possess $\mathrm{IC}_{50}$ values lower than $500 \mu \mathrm{M}$ against all three cell lines. Tetrazole-substituted compound $\mathbf{2}$ did not show activity, whereas triazole-substituted compound 1 was active. Generally, oxadiazole-substituted compounds 10, 11, and 12 exhibited good activity. The most effective cytotoxic agent against AsPC-1 and U251 cancer cell lines was found to be compound 11 with $\mathrm{IC}_{50}$ values of $16.8 \mu \mathrm{M}$, and $11.9 \mu \mathrm{M}$ respectively, followed by compound 12 with respective $\mathrm{IC}_{50}$ values of $62.1 \mu \mathrm{M}$, and $70.1 \mu \mathrm{M}$. On the other hand, these compounds showed no significant cytotoxicity at the concentrations used for the U87 cell line. 
(a)
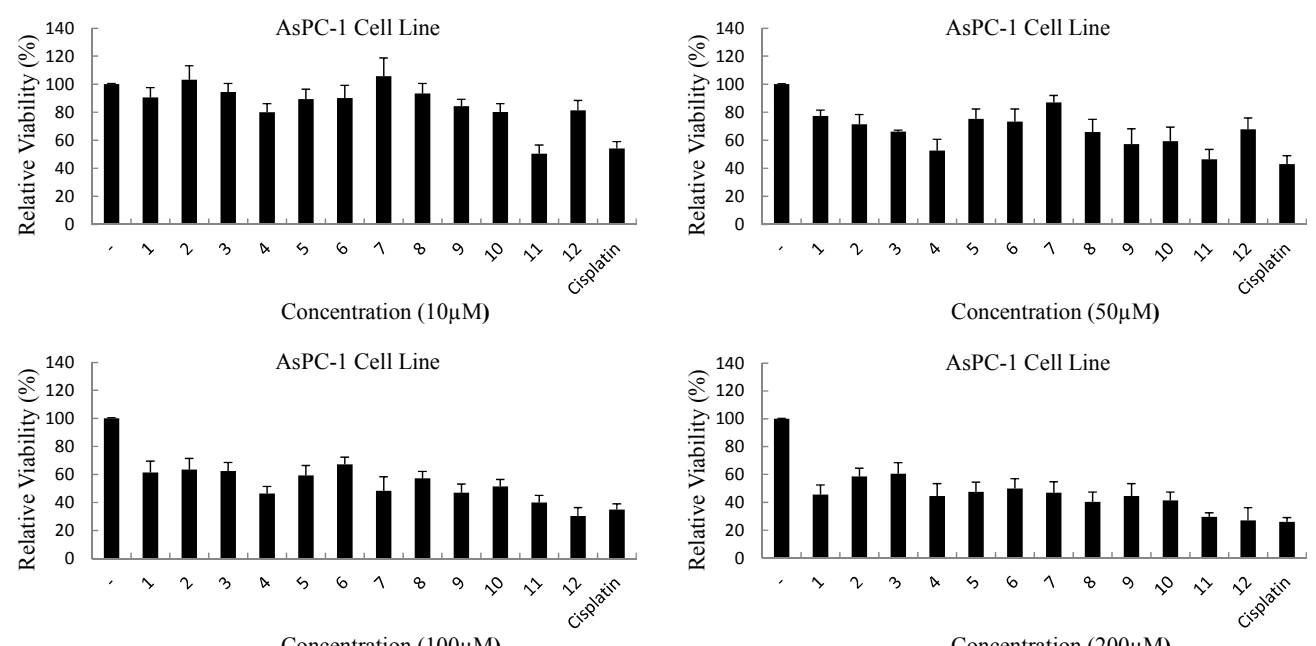

Concentration $(100 \mu \mathrm{M})$

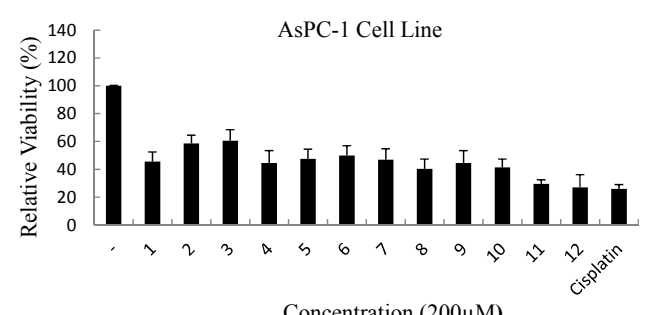

Concentration $(200 \mu \mathrm{M})$

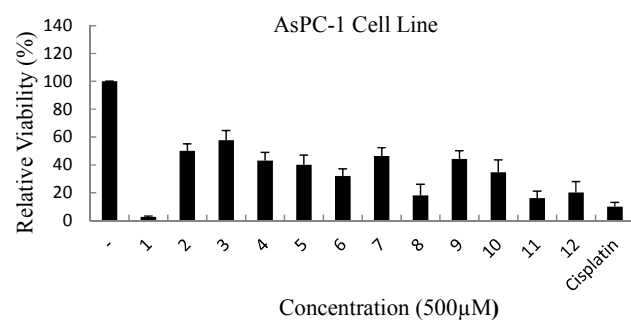

(b)
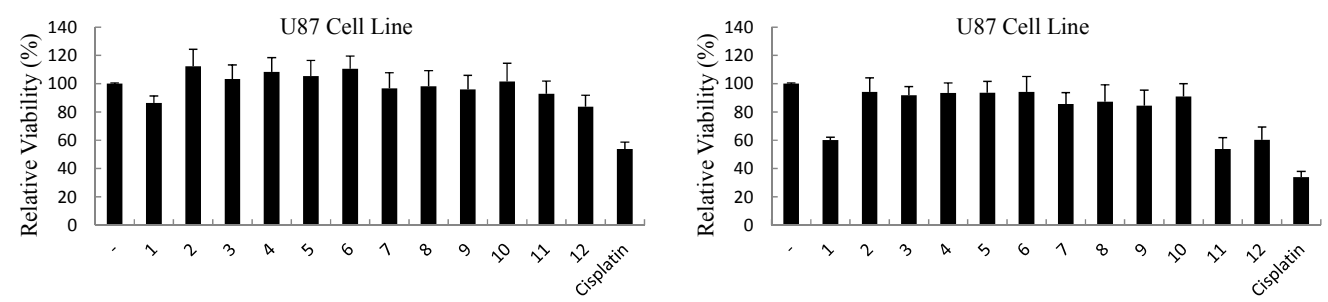

Concentration $(10 \mu \mathrm{M})$
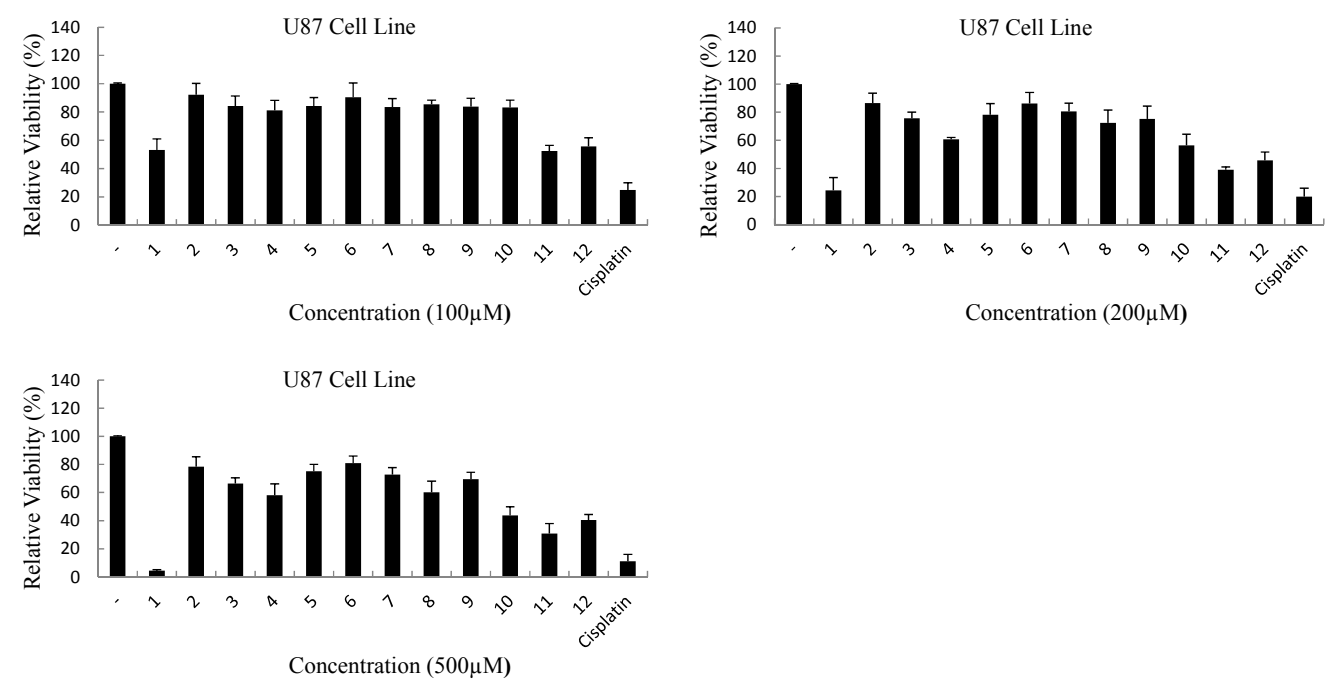

Figure 2. Cont. 
(c)
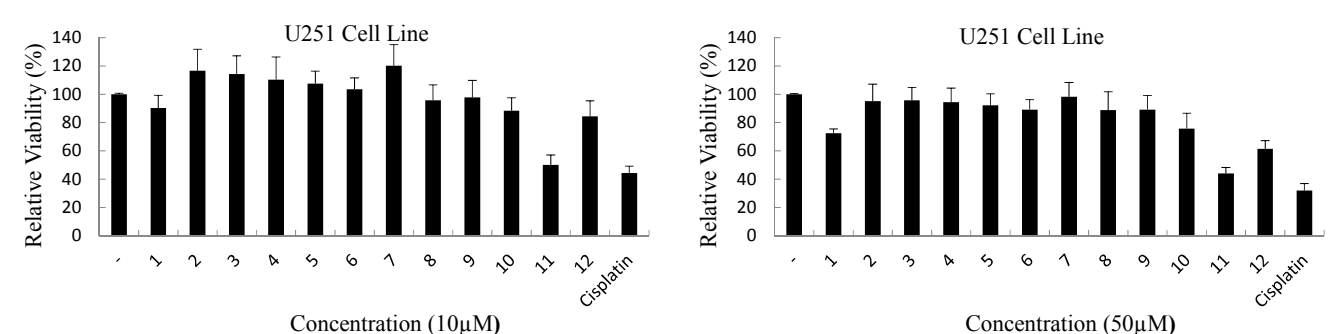

Concentration $(50 \mu \mathrm{M})$

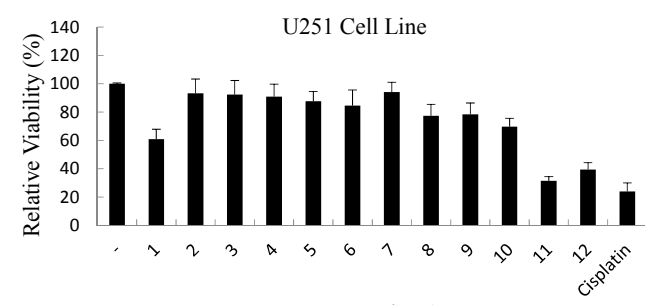

Concentration $(100 \mu \mathrm{M})$
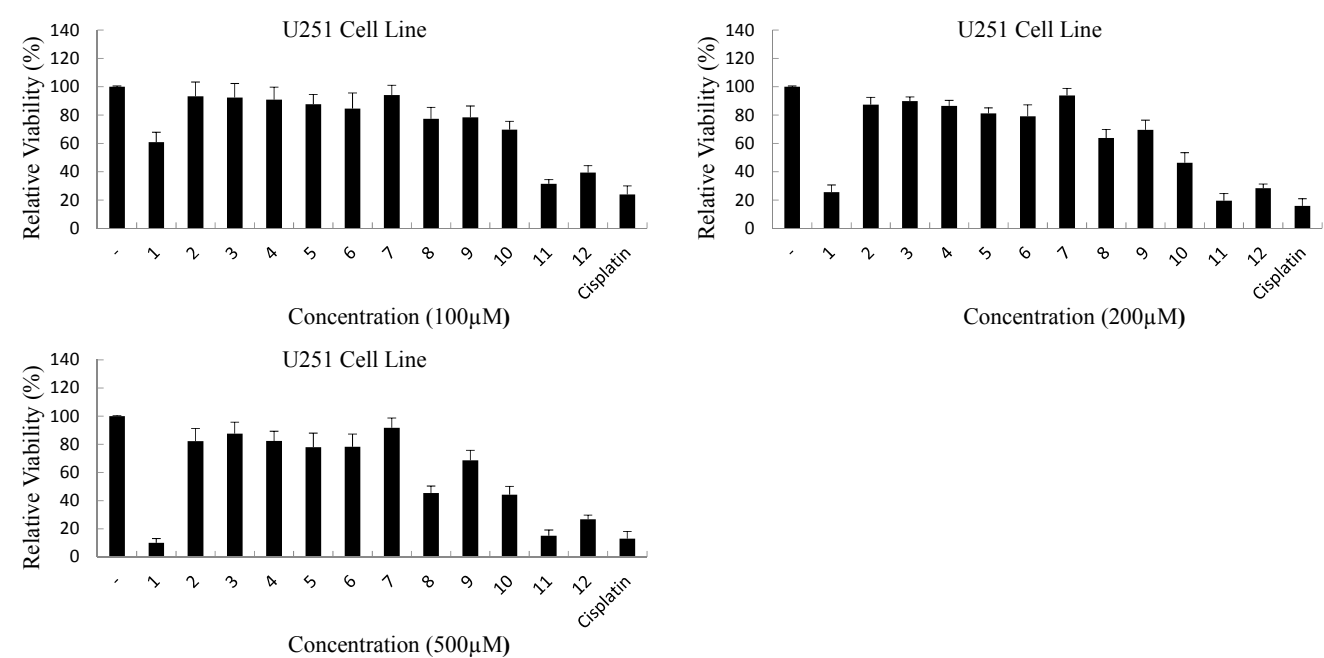

Concentration $(200 \mu \mathrm{M})$

Figure 2. Anticancer effects of compounds 1-12 and cisplatin at varying concentrations (10 $\mu \mathrm{M}, 50 \mu \mathrm{M}, 100 \mu \mathrm{M}, 200 \mu \mathrm{M}$, and $500 \mu \mathrm{M})$ against AsPC-1 (a); U87 (b); and U251 (c) cells.

Table 1. The cytotoxic effects of the compounds 1-12 on the AsPC-1, U87, and U251 cell lines.

\begin{tabular}{cccc}
\hline \multirow{2}{*}{ Compound } & \multicolumn{3}{c}{ IC $_{\mathbf{5 0}}(\boldsymbol{\mu M})$} \\
\cline { 2 - 4 } & AsPC1 Cell Line & U87 Cell Line & U251 Cell Line \\
\hline $\mathbf{1}$ & $166.7 \pm 10.6$ & $112.2 \pm 8.8$ & $126.9 \pm 15.6$ \\
$\mathbf{2}$ & $>500$ & $>500$ & $>500$ \\
$\mathbf{3}$ & $>500$ & $>500$ & $>500$ \\
$\mathbf{4}$ & $65.0 \pm 5.4$ & $>500$ & $>500$ \\
$\mathbf{5}$ & $215.7 \pm 29.7$ & $>500$ & $>500$ \\
$\mathbf{6}$ & $199.3 \pm 32.8$ & $>500$ & $>500$ \\
$\mathbf{7}$ & $236.2 \pm 36.4$ & $>500$ & $>500$ \\
$\mathbf{8}$ & $139.3 \pm 26.8$ & $>500$ & $393.1 \pm 60.4$ \\
$\mathbf{9}$ & $108.1 \pm 30.1$ & $>500$ & $>500$ \\
$\mathbf{1 0}$ & $110.5 \pm 20.4$ & $250.6 \pm 30.4$ & $166.6 \pm 25.1$ \\
$\mathbf{1 1}$ & $16.8 \pm 2.1$ & $127.4 \pm 12.8$ & $11.9 \pm 1.1$ \\
$\mathbf{1 2}$ & $62.1 \pm 7.8$ & $159.2 \pm 20.7$ & $70.1 \pm 8.8$ \\
\hline Cisplatin & $22.5 \pm 2.0$ & $14.8 \pm 1.4$ & $4.9 \pm 1.0$ \\
\hline
\end{tabular}

Among the tested compounds, compound $\mathbf{1 1}$ can be identified as the most promising anticancer agent. Thus, detail of concentration dependency of this compound $(0.1 \mu \mathrm{M}-1000 \mu \mathrm{M})$ was examined against 
AsPC-1, U87 and U251 cell lines (Figure 3a). Swelling ratio curves of AsPC-1 and U251 cell lines suggested biphasic mechanism of compound 11. Moreover, the activity of compound 11 against peripheral blood mononuclear cells (PBMC) $\left(\mathrm{IC}_{50}=\sim 1000 \mu \mathrm{M}\right)$ and Jurkat human leukemic T-cells $\left(\mathrm{IC}_{50}=90 \mu \mathrm{M}\right)$ indicated significant tumor selectivity in blood cells (more than 10 times) as shown in Figure $3 \mathrm{~b}$. This outcome pointed out the importance of 5-(4-methylphenyl)-1,3,4-oxadiazol-2-yl moiety for anticancer activity.

(a)

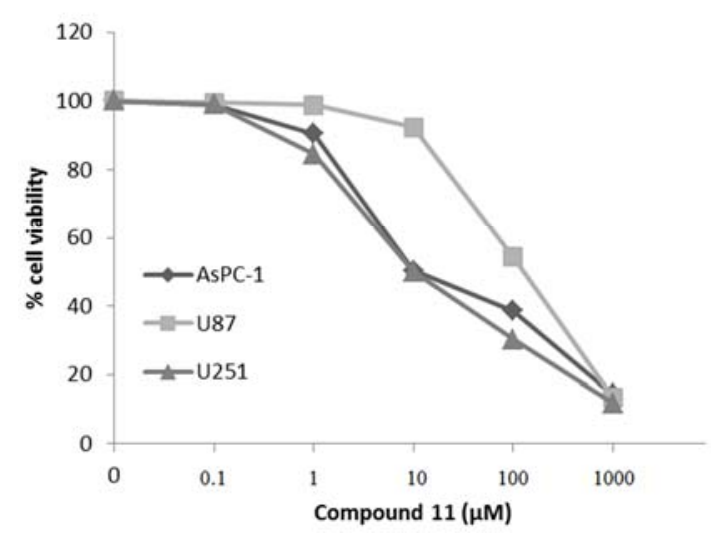

(b)

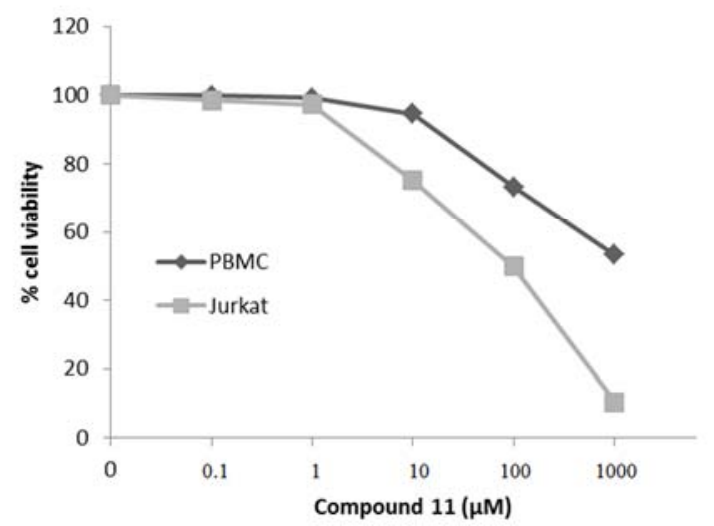

Figure 3. Effects of compound $\mathbf{1 1}$ on cell viability of AsPC-1, U87, U251 cell lines (a) and PBMC, Jurkat cell lines (b).

According to the MTT assay results, the most active anticancer compound $\mathbf{1 1}$ was chosen for the evaluation of apoptosis and necrosis in U251 cells, which was carried out with annexin V/ethidium homodimer III staining method. U251 cell lines were incubated with compound $\mathbf{1 1}$ or cisplatin at the IC 50 concentrations. U251 cells were stained and observed by fluorescence microscope (Figure 4). If the cells are colored green with annexin $\mathrm{V}$, and not stained red with ethidium homodimer III, the cells are judged to be apoptotic. On the other hand, the completely opposite results indicate necrosis. The apoptotic and necrotic effects of compound $\mathbf{1 1}$ were compared with cisplatin. The results indicate that cisplatin has only apoptotic effects at $24 \mathrm{~h}$ (Figure $4 \mathrm{~b}$ ). In contrast, U251 cell lines treated with compound 11 at $24 \mathrm{~h}$ showed late stage apoptotic or necrotic effect (almost all cells were colored yellow, data not shown). Therefore, the apoptotic/necrotic effects of compound 11 were tested against U251 cell line in earlier time (3h) at $\mathrm{IC}_{50}(11.9 \mu \mathrm{M})$ and low $(1.5 \mu \mathrm{M})$ concentrations. While compound 11 mainly induced necrosis at high concentration (Figure 4d), it induced apoptosis at low concentration (Figure 4e).

(a) Control (24h)

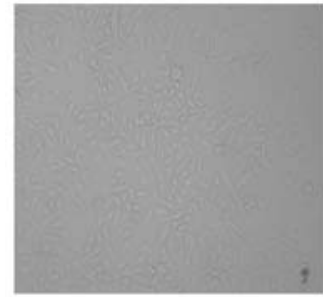

bright

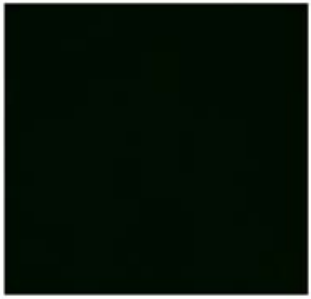

annexin V

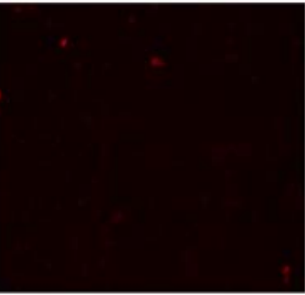

ethidium homodimer III

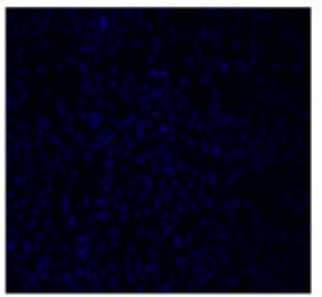

Hoechst33342

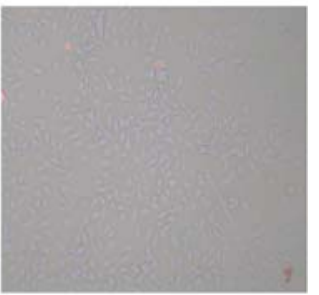

overlap

Figure 4. Cont. 
(b) Cisplatin (4.9 $\mu \mathrm{M}-24 \mathrm{~h})$

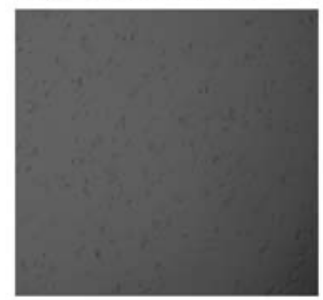

bright

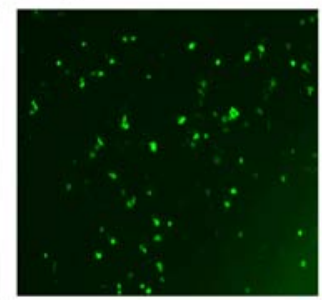

annexin V

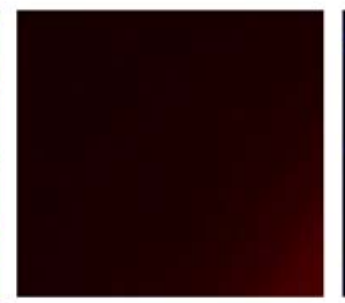

ethidium homodimer III

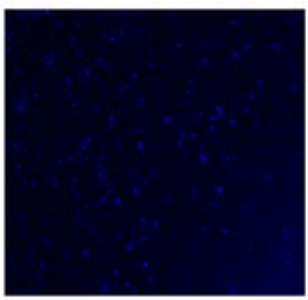

Hoechst33342

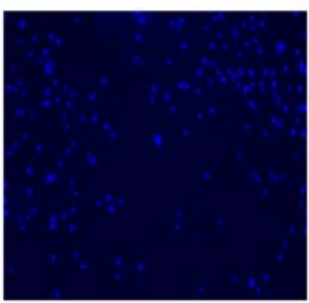

Hoechst 33342

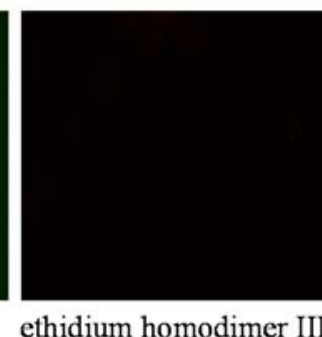

annexin V

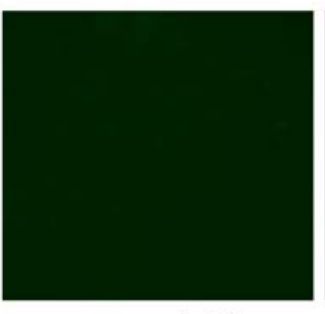

bright

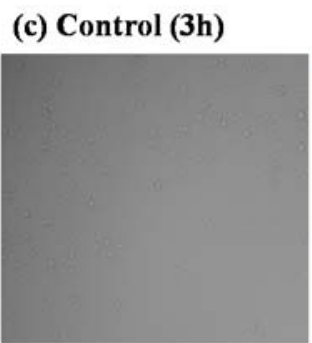

(d) Compound 11 (11.9 $\mu \mathrm{M}-3 \mathrm{~h})$

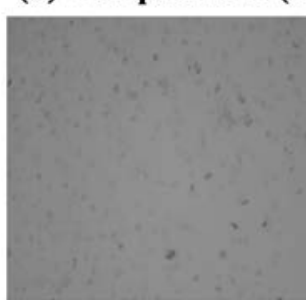

bright

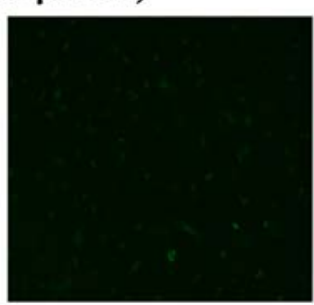

annexin V

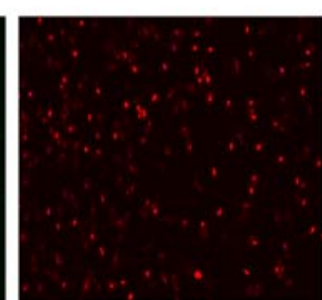

ethidium homodimer III

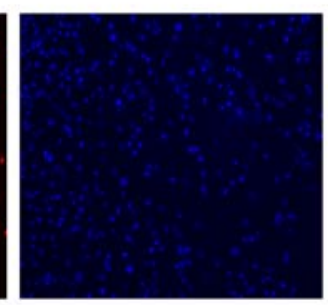

Hoechst33342

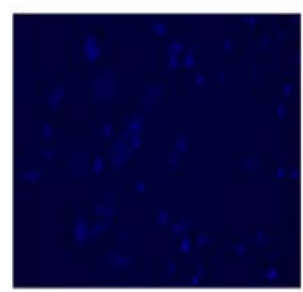

Hoechst33342

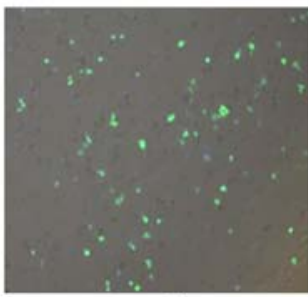

overlap

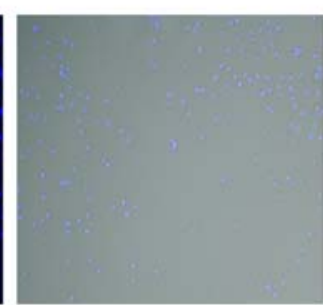

overlap (e) Compound $11(1.5 \mu \mathrm{M}$ - 3h)

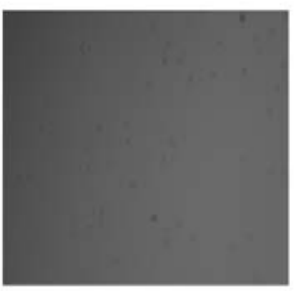

bright

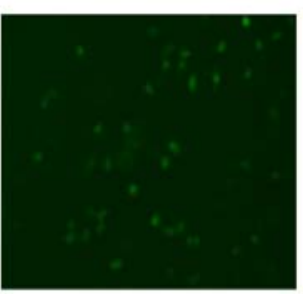

annexin V

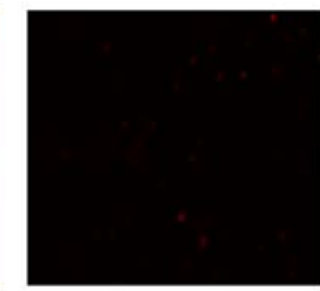

ethidium homodimer III

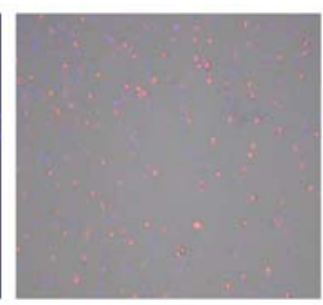

overlap

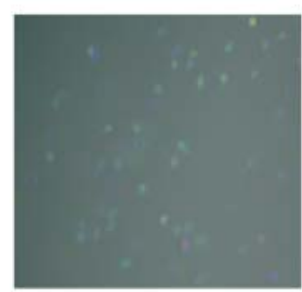

overlap

Figure 4. Cellular and nuclear morphological changes of U251 cells following exposure to IC50 concentrations of control (a); cisplatin $(4.9 \mu \mathrm{M})(\mathbf{b})$; for $24 \mathrm{~h}$ and control (c); compound $11(11.9 \mu \mathrm{M})(\mathbf{d})$; and $(1.5 \mu \mathrm{M})(\mathbf{e})$ for $3 \mathrm{~h}$.

The DNA cleavage activities of compound $\mathbf{1 1}$ and cisplatin at the $\mathrm{IC}_{50}$ concentrations in water and Tris/boric acid buffer in the presence and absent of the iron complex, $\mathrm{H}_{2} \mathrm{O}_{2}$ and ascorbic acid as an activator were studied using supercoiled pUC19 DNA (Figure 5). The reaction mixture was incubated at $37{ }^{\circ} \mathrm{C}$ for $1.5 \mathrm{~h}$ and then agarose gel electrophoresis was performed at $100 \mathrm{~V}$ for $40 \mathrm{~min}$. DNA was visualized by photographing the fluorescence of intercalated ethidium bromide under a UV illuminator. Control experiments using compound 11 with and without $\mathrm{FeSO}_{4}, \mathrm{H}_{2} \mathrm{O}_{2}$, and ascorbic acid showed that the DNA cleavage efficiency was clearly enhanced in the case of iron (II) complex system (Figure 5b). Thus, it is considered that DNA-cleavage was caused by oxygen activation. The DNA-cleaving 
efficiency of compound $\mathbf{1 1}$ was much greater than cisplatin. Compound $\mathbf{1 1}$ disintegrated pUC 19 DNA and these results suggest the relationship between the DNA cleavage and the cell death.

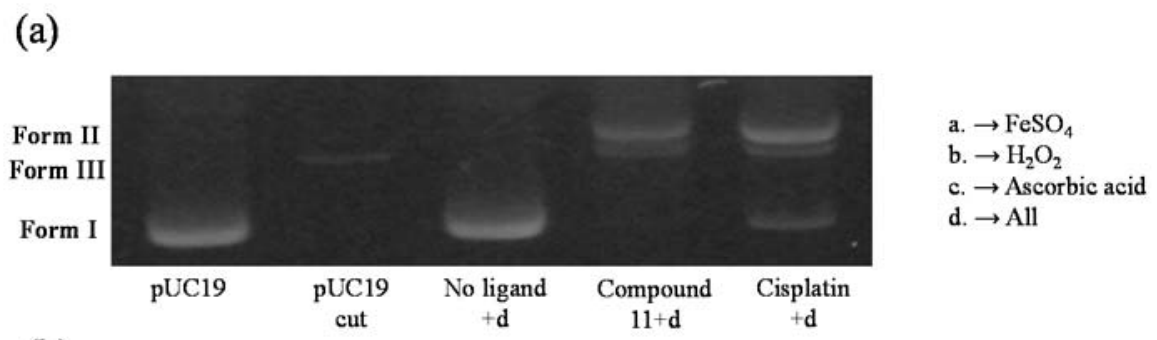

(b)

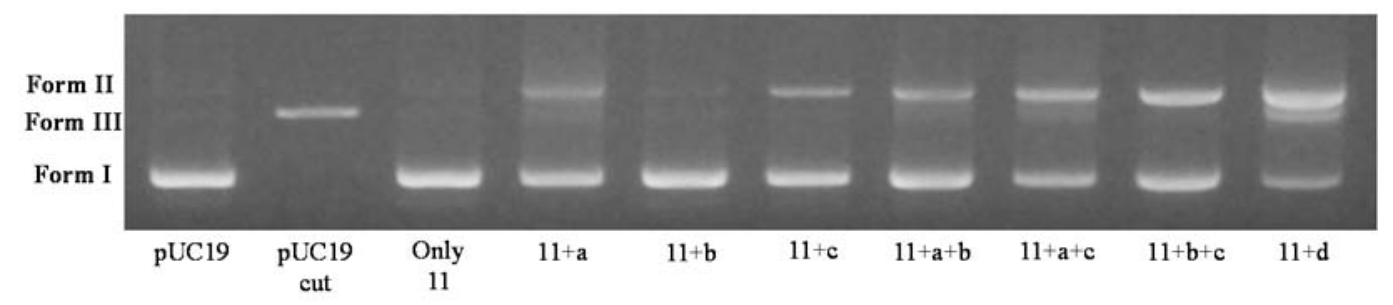

Figure 5. The DNA cleaving capability of the Fe(II) complexes of compound $\mathbf{1 1}$ and cisplatin in the presence of the iron (II) complex (a) and control experiments using compound $\mathbf{1 1}$ in the presence and absence of $\mathrm{FeSO}_{4}, \mathrm{H}_{2} \mathrm{O}_{2}$, and ascorbic acid (b). It was studied by the relaxation of the supercoiled pUC19 DNA and analyzed by agarose-gel electrophoresis.

\section{Experimental Section}

\subsection{Chemistry}

All reagents were purchased from commercial suppliers and were used without further purification. Melting points were determined on an Electrothermal 9100 melting point apparatus (Weiss-Gallenkamp, Loughborough, UK) and were uncorrected. IR spectra were recorded on a Shimadzu 8400 FT-IR spectrophotometer (Shimadzu, Tokyo, Japan). ${ }^{1} \mathrm{H}-\mathrm{NMR}$ and ${ }^{13} \mathrm{C}-\mathrm{NMR}$ spectra were recorded on a Varian Mercury-400 FT-NMR spectrometer (Agilent, Palo Alto, CA, USA). Mass spectra were recorded on an Agilent LC-MSD-Trap-SL Mass spectrometer (Agilent Technologies). Elemental analyses were performed on a Perkin Elmer EAL 240 elemental analyzer (Perkin-Elmer, Norwalk, CT, USA). Thin Layer Chromatography (TLC) was performed on TLC silica gel $60 \mathrm{~F}_{254}$ aluminium sheets (Merck, Darmstadt, Germany) using petroleum ether:ethyl acetate $(3: 1 v / v)$ as an eluent.

General Procedures for the Synthesis of Compounds

\section{1-(2-Thienyl)-3-(4-chlorophenyl)-2-propen-1-one}

A mixture of 2-acetylthiophene $(0.04 \mathrm{~mol}), 4$-chlorobenzaldehyde $(0.04 \mathrm{~mol})$ and $10 \%$ aqueous sodium hydroxide solution $(10 \mathrm{~mL})$ in ethanol $(30 \mathrm{~mL})$ was stirred at room temperature for $6-8 \mathrm{~h}$. The progress of the reaction was checked by TLC. Upon completion, the reaction mixture was poured into crushed ice. The precipitated solid was filtered, washed with water, and dried. The product was crystallized from ethanol [36]. 


\section{5-(4-Chlorophenyl)-3-(2-thienyl)-2-pyrazoline}

A mixture of 1-(2-thienyl)-3-(4-chlorophenyl)-2-propen-1-one (0.01 mol) and hydrazine hydrate (80\%) $(0.02 \mathrm{~mol})$ in ethanol $(30 \mathrm{~mL})$ was refluxed for $5 \mathrm{~h}$. The reaction mixture was cooled and kept at $0{ }^{\circ} \mathrm{C}$ overnight. The resulting solid was filtered and dried. The product was crystallized from ethanol [36].

\section{1-(Chloroacetyl)-3-(2-thienyl)-5-(4-chlorophenyl)-2-pyrazoline}

5-(4-Chlorophenyl)-3-(2-thienyl)-2-pyrazoline $(0.01 \mathrm{~mol})$ and triethylamine $(0.01 \mathrm{~mol})$ were dissolved in toluene $(30 \mathrm{~mL})$. The reaction mixture was cooled in an ice bath, and chloroacetyl chloride $(0.01 \mathrm{~mol})$ was added dropwise with constant stirring. The mixture thus obtained was further agitated for $1 \mathrm{~h}$ at room temperature. The solvent was evaporated to dryness under reduced pressure. The residue was washed with water, and the product was recrystallized from ethanol [36].

\section{1-[(Aryl)thioacetyl]-3-(2-thienyl)-5-(4-chlorophenyl)-2-pyrazolines (1-12)}

A mixture of 1-(chloroacetyl)-3-(2-thienyl)-5-(4-chlorophenyl)-2-pyrazoline (0.005 mol) and aryl thiol $(0.005 \mathrm{~mol})$ was treated in acetone $(30 \mathrm{~mL})$ at room temperature for $8 \mathrm{~h}$. The solvent was evaporated, the residue was washed with water and recrystallized from ethanol [37].

1-[(4-Methyl-4H-1,2,4-triazol-3-yl)thioacetyl]-3-(2-thienyl)-5-(4-chlorophenyl)-2-pyrazoline (1). Yield: 83\%; M.p. $165.1^{\circ} \mathrm{C}$. IR (KBr) $v_{\max }\left(\mathrm{cm}^{-1}\right)$ : 3124 (aromatic C-H), 2922 (aliphatic C-H asymmetric), 1666 $(\mathrm{C}=\mathrm{O}), 1490,1458,1417(\mathrm{C}=\mathrm{N}$ and $\mathrm{C}=\mathrm{C}), 1375,1203,1085,1026(\mathrm{C}-\mathrm{N}), 952,817(\mathrm{C}-\mathrm{H}$ out of plane deformation). ${ }^{1} \mathrm{H}-\mathrm{NMR}\left(400 \mathrm{MHz}, \delta \mathrm{ppm}, \mathrm{DMSO}-d_{6}\right): 3.16\left(1 \mathrm{H}, \mathrm{dd}, J_{\mathrm{AX}}=4.40 \mathrm{~Hz}, J_{\mathrm{AB}}=17.60 \mathrm{~Hz}\right.$, pyrazoline $\left.\mathrm{C}_{4}-\mathrm{H}_{\mathrm{A}}\right), 3.58\left(3 \mathrm{H}, \mathrm{CH}_{3}\right), 3.89\left(1 \mathrm{H}, \mathrm{dd}, J_{\mathrm{BX}}=11.60 \mathrm{~Hz}, J_{\mathrm{BA}}=18.00 \mathrm{~Hz}\right.$, pyrazoline $\left.\mathrm{C}_{4}-\mathrm{H}_{\mathrm{B}}\right)$, $4.33(1 \mathrm{H}, \mathrm{d}, J=15.20 \mathrm{~Hz}$, geminal proton, CO-C $\underline{H}), 4.46(1 \mathrm{H}, \mathrm{d}, J=15.60 \mathrm{~Hz}$, geminal proton, CO-C $\underline{H})$, $5.57\left(1 \mathrm{H}, \mathrm{dd}, J_{\mathrm{AX}}=4.80 \mathrm{~Hz}, J_{\mathrm{BX}}=11.60 \mathrm{~Hz}\right.$, pyrazoline $\left.\mathrm{C}_{5}-\mathrm{Hx}\right), 7.16(1 \mathrm{H}, \mathrm{m}), 7.26(2 \mathrm{H}, \mathrm{d}, J=8.80 \mathrm{~Hz})$, $7.38(2 \mathrm{H}, \mathrm{d}, J=8.80 \mathrm{~Hz}), 7.48\left(1 \mathrm{H}, \mathrm{dd}, J=1.20 \mathrm{~Hz}, 4.00 \mathrm{~Hz}\right.$, thiophene $\left.\mathrm{C}_{3}-\mathrm{H}\right), 7.78(1 \mathrm{H}, \mathrm{dd}, J=1.20 \mathrm{~Hz}$, $5.20 \mathrm{~Hz}$, thiophene $\left.\mathrm{C}_{5}-\mathrm{H}\right), 8.52\left(1 \mathrm{H}, \mathrm{s}\right.$, triazole). ${ }^{13} \mathrm{C}-\mathrm{NMR}\left(100 \mathrm{MHz}, \mathrm{DMSO}-d_{6}\right) \delta(\mathrm{ppm}): 31.49\left(\mathrm{CH}_{3}\right.$, triazole), $39.72\left(\mathrm{CH}_{2}, \mathrm{~S}-\mathrm{CH}_{2}\right), 43.36\left(\mathrm{CH}_{2}\right.$, pyrazoline $\left.\mathrm{C}_{4}\right), 60.04\left(\mathrm{CH}\right.$, pyrazoline $\left.\mathrm{C}_{5}\right), 128.27(2 \mathrm{CH}$, aromatic), $128.81(\mathrm{CH}$, aromatic), 129.28 (2CH, aromatic), 130.83 (C, aromatic), $131.73(\mathrm{CH}$, aromatic), 132.61 (CH, aromatic), 134.23 (C, aromatic), 141.05 (C, aromatic), 146.94 (CH, aromatic), 149.16 (C, aromatic), $151.95\left(\mathrm{C}\right.$, pyrazoline $\left.\mathrm{C}_{3}\right), 164.96(\mathrm{C}, \mathrm{C}=\mathrm{O})$. Anal. Calcd. for $\mathrm{C}_{18} \mathrm{H}_{16} \mathrm{ClN}_{5} \mathrm{OS}_{2}$ : $\mathrm{C}, 51.73 ; \mathrm{H}$, 3.86; N, 16.76. Found: C, 51.66; H, 3.89; N, 16.81. MS (ESI) $(\mathrm{m} / \mathrm{z}): 418[\mathrm{M}+\mathrm{H}]^{+}$.

1-[(1-Methyl-1H-tetrazol-5-yl)thioacetyl]-3-(2-thienyl)-5-(4-chlorophenyl)-2-pyrazoline (2). Yield: 86\%; M.p. $108.2^{\circ} \mathrm{C}$. IR (KBr) $v_{\max }\left(\mathrm{cm}^{-1}\right): 3107$ (aromatic C-H), 2941 (aliphatic C-H asymmetric), $1658(\mathrm{C}=\mathrm{O})$, 1463, $1417(\mathrm{C}=\mathrm{N}$ and $\mathrm{C}=\mathrm{C}), 1396,1278,1219,1089,1026(\mathrm{C}-\mathrm{N}), 968,837,819(\mathrm{C}-\mathrm{H}$ out of plane deformation). ${ }^{1} \mathrm{H}-\mathrm{NMR}\left(400 \mathrm{MHz}, \delta \mathrm{ppm}, \mathrm{DMSO}-d_{6}\right): 3.22\left(1 \mathrm{H}, \mathrm{dd}, J_{\mathrm{AX}}=4.80 \mathrm{~Hz}, J_{\mathrm{AB}}=18.40 \mathrm{~Hz}\right.$, pyrazoline $\left.\mathrm{C}_{4}-\mathrm{H}_{\mathrm{A}}\right), 3.91\left(1 \mathrm{H}, \mathrm{dd}, J_{\mathrm{BX}}=11.60 \mathrm{~Hz}, J_{\mathrm{BA}}=18.00 \mathrm{~Hz}\right.$, pyrazoline $\left.\mathrm{C}_{4}-\mathrm{H}_{\mathrm{B}}\right), 3.95\left(3 \mathrm{H}, \mathrm{CH}_{3}\right), 4.57$ $(1 \mathrm{H}, \mathrm{d}, J=15.60 \mathrm{~Hz}$, geminal proton, $\mathrm{CO}-\mathrm{C} \underline{H}), 4.71(1 \mathrm{H}, \mathrm{d}, J=16.00 \mathrm{~Hz}$, geminal proton, CO-C $\underline{H}), 5.59$ $\left(1 \mathrm{H}, \mathrm{dd}, J_{\mathrm{AX}}=4.80 \mathrm{~Hz}, J_{\mathrm{BX}}=12.00 \mathrm{~Hz}\right.$, pyrazoline $\left.\mathrm{C}_{5}-\mathrm{Hx}\right), 7.17(1 \mathrm{H}, \mathrm{m}), 7.26(2 \mathrm{H}, \mathrm{d}, J=8.40 \mathrm{~Hz})$, $7.38(2 \mathrm{H}, \mathrm{d}, J=8.80 \mathrm{~Hz}), 7.50\left(1 \mathrm{H}, \mathrm{dd}, J=1.20 \mathrm{~Hz}, 3.60 \mathrm{~Hz}\right.$, thiophene $\left.\mathrm{C}_{3}-\mathrm{H}\right), 7.79(1 \mathrm{H}, \mathrm{dd}, J=0.80 \mathrm{~Hz}$, $5.20 \mathrm{~Hz}$, thiophene $\left.\mathrm{C}_{5}-\mathrm{H}\right) .{ }^{13} \mathrm{C}-\mathrm{NMR}\left(100 \mathrm{MHz}, \mathrm{DMSO}-d_{6}\right) \delta(\mathrm{ppm}): 34.32\left(\mathrm{CH}_{3}\right.$, tetrazole $), 37.15\left(\mathrm{CH}_{2}\right.$, 
S-CH$), 43.40\left(\mathrm{CH}_{2}\right.$, pyrazoline $\left.\mathrm{C}_{4}\right), 60.16\left(\mathrm{CH}\right.$, pyrazoline $\left.\mathrm{C}_{5}\right), 128.26(2 \mathrm{CH}$, aromatic), $128.84(\mathrm{CH}$, aromatic), $129.29(2 \mathrm{CH}$, aromatic), $130.96(\mathrm{C}$, aromatic $), 131.90(\mathrm{CH}$, aromatic $), 132.66(\mathrm{CH}$, aromatic), 134.14 (C, aromatic), 140.96 (C, aromatic), 152.29 (C, pyrazoline $\mathrm{C}_{3}$ ), 153.97 (C, aromatic), 164.19 (C,

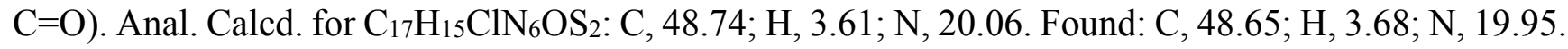
$\operatorname{MS}(\mathrm{ESI})(\mathrm{m} / \mathrm{z}): 419[\mathrm{M}+\mathrm{H}]^{+}, 420[\mathrm{M}+\mathrm{H}]^{++}$.

1-[(1-Phenyl-1H-tetrazol-5-yl)thioacetyl]-3-(2-thienyl)-5-(4-chlorophenyl)-2-pyrazoline (3). Yield: 84\%; M.p. $183.3^{\circ} \mathrm{C}$. IR (KBr) $v_{\max }\left(\mathrm{cm}^{-1}\right)$ : 3107 (aromatic C-H), 2933 (aliphatic C-H asymmetric), $1656(\mathrm{C}=\mathrm{O})$, 1498, 1462, $1423(\mathrm{C}=\mathrm{N}$ and $\mathrm{C}=\mathrm{C}), 1388,1220,1089,1012(\mathrm{C}-\mathrm{N}), 831$ (C-H out of plane deformation). ${ }^{1} \mathrm{H}-\mathrm{NMR}\left(400 \mathrm{MHz}, \delta \mathrm{ppm}, \mathrm{DMSO}-d_{6}\right): 3.23\left(1 \mathrm{H}, \mathrm{dd}, J_{\mathrm{AX}}=4.40 \mathrm{~Hz}, J_{\mathrm{AB}}=18.00 \mathrm{~Hz}\right.$, pyrazoline $\left.\mathrm{C}_{4}-\mathrm{H}_{\mathrm{A}}\right)$, $3.94\left(1 \mathrm{H}, \mathrm{dd}, J_{\mathrm{BX}}=11.60 \mathrm{~Hz}, J_{\mathrm{BA}}=18.00 \mathrm{~Hz}\right.$, pyrazoline $\left.\mathrm{C}_{4}-\mathrm{H}_{\mathrm{B}}\right), 4.69(1 \mathrm{H}, \mathrm{d}, J=16.00 \mathrm{~Hz}$, geminal proton, CO-C $\underline{H}), 4.83(1 \mathrm{H}, \mathrm{d}, J=16.40 \mathrm{~Hz}$, geminal proton, CO-C $\underline{H}), 5.60\left(1 \mathrm{H}, \mathrm{dd}, J_{\mathrm{Ax}}=4.00 \mathrm{~Hz}\right.$, $J_{\mathrm{BX}}=11.20 \mathrm{~Hz}$, pyrazoline $\left.\mathrm{C}_{5}-\mathrm{Hx}\right), 7.18(1 \mathrm{H}, \mathrm{m}), 7.27(2 \mathrm{H}, \mathrm{d}, J=8.40 \mathrm{~Hz}), 7.38(2 \mathrm{H}, \mathrm{d}, J=8.80 \mathrm{~Hz})$, $7.51\left(1 \mathrm{H}, \mathrm{dd}, J=1.20 \mathrm{~Hz}, 3.60 \mathrm{~Hz}\right.$, thiophene $\left.\mathrm{C}_{3}-\mathrm{H}\right), 7.64-7.68(5 \mathrm{H}, \mathrm{m}), 7.80(1 \mathrm{H}, \mathrm{dd}, J=1.20 \mathrm{~Hz}, 4.80 \mathrm{~Hz}$, thiophene $\left.\mathrm{C}_{5}-\mathrm{H}\right) .{ }^{13} \mathrm{C}-\mathrm{NMR}\left(100 \mathrm{MHz}, \mathrm{DMSO}-d_{6}\right) \delta(\mathrm{ppm}): 37.35\left(\mathrm{CH}_{2}, \mathrm{~S}-\mathrm{CH}_{2}\right), 43.41\left(\mathrm{CH}_{2}\right.$, pyrazoline $\left.\mathrm{C}_{4}\right), 60.21$ ( $\mathrm{CH}$, pyrazoline $\left.\mathrm{C}_{5}\right), 125.10$ (2CH, aromatic), 128.27 (2CH, aromatic), 128.87 ( $\mathrm{CH}$, aromatic), 129.29 (2CH, aromatic), $130.75(2 \mathrm{CH}$, aromatic), $131.01(\mathrm{CH}$, aromatic), $131.34(\mathrm{CH}$, aromatic), 131.98 (CH, aromatic), 132.65 (C, aromatic), 133.70 (C, aromatic), 134.13 (C, aromatic), 140.96 (C, aromatic), 152.38 (C, pyrazoline $\mathrm{C}_{3}$ ), $154.65\left(\mathrm{C}\right.$, aromatic), $163.92(\mathrm{C}, \mathrm{C}=\mathrm{O})$. Anal. Calcd. for $\mathrm{C}_{22} \mathrm{H}_{17} \mathrm{ClN}_{6} \mathrm{OS}_{2}$ : $\mathrm{C}$, 54.94; H, 3.56; N, 17.47. Found: C, 54.99; H, 3.58; N, 17.51. MS (ESI) (m/z): $481[\mathrm{M}+\mathrm{H}]^{+}$.

1-[(1-(4-Hydroxyphenyl)-1H-tetrazol-5-yl)thioacetyl]-3-(2-thienyl)-5-(4-chlorophenyl)-2-pyrazoline (4). Yield: 71\%; M.p. $145.7{ }^{\circ} \mathrm{C}$. IR (KBr) $v_{\max }\left(\mathrm{cm}^{-1}\right)$ : $3601(\mathrm{O}-\mathrm{H}), 3107$ (aromatic C-H), 2932 (aliphatic $\mathrm{C}-\mathrm{H}$ asymmetric), $1641(\mathrm{C}=\mathrm{O}), 1516,1454,1415(\mathrm{C}=\mathrm{N}$ and $\mathrm{C}=\mathrm{C}), 1278,1228,1087(\mathrm{C}-\mathrm{N}), 837,823$ (C-H out of plane deformation). ${ }^{1} \mathrm{H}-\mathrm{NMR}\left(400 \mathrm{MHz}, \delta \mathrm{ppm}, \mathrm{DMSO}-d_{6}\right): 3.22\left(1 \mathrm{H}, \mathrm{dd}, J_{\mathrm{AX}}=4.80 \mathrm{~Hz}\right.$, $J_{\mathrm{AB}}=18.00 \mathrm{~Hz}$, pyrazoline $\left.\mathrm{C}_{4}-\mathrm{H}_{\mathrm{A}}\right), 3.93\left(1 \mathrm{H}, \mathrm{dd}, J_{\mathrm{BX}}=11.60 \mathrm{~Hz}, J_{\mathrm{BA}}=18.00 \mathrm{~Hz}\right.$, pyrazoline $\left.\mathrm{C}_{4}-\mathrm{H}_{\mathrm{B}}\right)$, $4.65(1 \mathrm{H}, \mathrm{d}, J=16.00 \mathrm{~Hz}$, geminal proton, $\mathrm{CO}-\mathrm{C} \underline{H}), 4.77(1 \mathrm{H}, \mathrm{d}, J=16.00 \mathrm{~Hz}$, geminal proton, CO-C $\underline{H})$, $5.60\left(1 \mathrm{H}, \mathrm{dd}, J_{\mathrm{AX}}=4.40 \mathrm{~Hz}, J_{\mathrm{BX}}=11.60 \mathrm{~Hz}\right.$, pyrazoline $\left.\mathrm{C}_{5}-\mathrm{Hx}\right), 6.87(2 \mathrm{H}, \mathrm{d}, J=8.80 \mathrm{~Hz}), 7.17(1 \mathrm{H}, \mathrm{m})$, 7.26-7.33 (4H, m), $7.37(2 \mathrm{H}, \mathrm{d}, J=8.40 \mathrm{~Hz}), 7.51\left(1 \mathrm{H}, \mathrm{d}, J=3.60 \mathrm{~Hz}\right.$, thiophene $\left.\mathrm{C}_{3}-\mathrm{H}\right), 7.79(1 \mathrm{H}, \mathrm{d}$, $J=5.20 \mathrm{~Hz}$, thiophene $\left.\mathrm{C}_{5}-\mathrm{H}\right), 9.35(1 \mathrm{H}, \mathrm{s}) .{ }^{13} \mathrm{C}-\mathrm{NMR}\left(100 \mathrm{MHz}, \mathrm{DMSO}-d_{6}\right) \delta(\mathrm{ppm}): 37.04\left(\mathrm{CH}_{2}\right.$, S-CH 2$), 43.40\left(\mathrm{CH}_{2}\right.$, pyrazoline $\left.\mathrm{C}_{4}\right), 60.20\left(\mathrm{CH}\right.$, pyrazoline $\left.\mathrm{C}_{5}\right), 117.35(2 \mathrm{CH}$, aromatic), $122.57(\mathrm{C}$, aromatic), $126.65(2 \mathrm{CH}$, aromatic), $128.27(2 \mathrm{CH}$, aromatic), $128.85(\mathrm{CH}$, aromatic), $129.29(2 \mathrm{CH}$, aromatic), $130.96(\mathrm{CH}$, aromatic), $131.90(\mathrm{CH}$, aromatic), $132.64(\mathrm{CH}$, aromatic), 134.16 (C, aromatic), 140.98 (C, aromatic), 152.28 (C, pyrazoline $\mathrm{C}_{3}$ ), 154.65 (C, aromatic), 163.04 (C, aromatic), 164.05 $(\mathrm{C}, \mathrm{C}=\mathrm{O})$. Anal. Calcd. for $\mathrm{C}_{22} \mathrm{H}_{17} \mathrm{ClN}_{6} \mathrm{O}_{2} \mathrm{~S}_{2}: \mathrm{C}, 53.17 ; \mathrm{H}, 3.45 ; \mathrm{N}, 16.91$. Found: $\mathrm{C}, 53.21 ; \mathrm{H}, 3.54 ; \mathrm{N}$, 16.96. MS (ESI) $(\mathrm{m} / \mathrm{z}): 497[\mathrm{M}+\mathrm{H}]^{+}, 498[\mathrm{M}+\mathrm{H}]^{++}$.

1-[(1-(2-(Dimethylamino)ethyl)-1H-tetrazol-5-yl)thioacetyl]-3-(2-thienyl)-5-(4-chlorophenyl)-2-pyrazoline (5). Yield: 76\%; M.p. $112.1^{\circ} \mathrm{C}$. IR (KBr) $v_{\max }\left(\mathrm{cm}^{-1}\right)$ : 3091 (aromatic C-H), 2943, 2827 (aliphatic C-H asymmetric), $1654(\mathrm{C}=\mathrm{O}), 1452,1413(\mathrm{C}=\mathrm{N}$ and $\mathrm{C}=\mathrm{C}), 1394,1220,1093,1029(\mathrm{C}-\mathrm{N}), 831,817(\mathrm{C}-\mathrm{H}$ out of plane deformation). ${ }^{1} \mathrm{H}-\mathrm{NMR}\left(400 \mathrm{MHz}, \delta \mathrm{ppm}, \mathrm{DMSO}-\mathrm{d}_{6}\right): 2.13(6 \mathrm{H}, \mathrm{s}), 2.64(2 \mathrm{H}, \mathrm{t}, J=6.40 \mathrm{~Hz}$, $12.00 \mathrm{~Hz}), 3.22\left(1 \mathrm{H}, \mathrm{dd}, J_{\mathrm{AX}}=4.80 \mathrm{~Hz}, J_{\mathrm{AB}}=18.00 \mathrm{~Hz}\right.$, pyrazoline $\left.\mathrm{C}_{4}-\mathrm{H}_{\mathrm{A}}\right), 3.92\left(1 \mathrm{H}, \mathrm{dd}, J_{\mathrm{BX}}=11.60 \mathrm{~Hz}\right.$, 
$J_{\mathrm{BA}}=17.60 \mathrm{~Hz}$, pyrazoline $\left.\mathrm{C}_{4}-\mathrm{HB}\right), 4.38(2 \mathrm{H}, \mathrm{t}, J=6.00 \mathrm{~Hz}, 12.00 \mathrm{~Hz}), 4.57(1 \mathrm{H}, \mathrm{d}, J=15.60 \mathrm{~Hz}$, geminal proton, $\mathrm{CO}-\mathrm{C} \underline{\mathrm{H}}), 4.71(1 \mathrm{H}, \mathrm{d}, J=16.00 \mathrm{~Hz}$, geminal proton, CO-C $\underline{H}), 5.59\left(1 \mathrm{H}, \mathrm{dd}, J_{\mathrm{AX}}=4.80 \mathrm{~Hz}\right.$, $J_{\mathrm{BX}}=12.00 \mathrm{~Hz}$, pyrazoline $\left.\mathrm{C}_{5}-\mathrm{Hx}\right), 7.17(1 \mathrm{H}, \mathrm{m}), 7.26(2 \mathrm{H}, \mathrm{d}, J=8.80 \mathrm{~Hz}), 7.38(2 \mathrm{H}, \mathrm{d}, J=8.80 \mathrm{~Hz})$, $7.49\left(1 \mathrm{H}, \mathrm{dd}, J=0.80,3.60 \mathrm{~Hz}\right.$, thiophene $\left.\mathrm{C}_{3}-\mathrm{H}\right), 7.79\left(1 \mathrm{H}, \mathrm{dd}, J=5.20,0.80 \mathrm{~Hz}\right.$, thiophene $\left.\mathrm{C}_{5}-\mathrm{H}\right)$. ${ }^{13} \mathrm{C}-\mathrm{NMR}\left(100 \mathrm{MHz}, \mathrm{DMSO}-d_{6}\right) \delta(\mathrm{ppm}): 37.46\left(\mathrm{CH}_{2}, \mathrm{~S}-\mathrm{CH}_{2}\right), 43.38\left(\mathrm{CH}_{2}\right.$, pyrazoline $\left.\mathrm{C}_{4}\right), 45.65\left(2 \mathrm{CH}_{3}\right.$, $\left.\mathrm{H}_{3} \mathrm{C}-\mathrm{N}-\mathrm{CH}_{3}\right), 45.99\left(\mathrm{CH}_{2}, \mathrm{CH}_{2}\right.$-tetrazole $), 57.84\left(\mathrm{CH}_{2}, \mathrm{CH}_{2}-\mathrm{N}\left(\mathrm{CH}_{3}\right)_{2}\right), 60.15\left(\mathrm{CH}\right.$, pyrazoline $\left.\mathrm{C}_{5}\right)$, 128.25 (2CH, aromatic), $128.84(\mathrm{CH}$, aromatic), 129.29 (2CH, aromatic), $130.97(\mathrm{CH}$, aromatic), 131.91 (CH, aromatic), 132.64 (C, aromatic), 134.15 (C, aromatic), 140.99 (C, aromatic), 152.25 (C, pyrazoline $\left.\mathrm{C}_{3}\right), 154.19$ (C, aromatic), 164.23 (C, $\mathrm{C}=\mathrm{O}$ ). Anal. Calcd. for $\mathrm{C}_{20} \mathrm{H}_{22} \mathrm{ClN}_{7} \mathrm{OS}_{2}$ : C, 50.46; H, 4.66; N, 20.60. Found: C, 50.42; H, 4.69; N, 20.57. MS (ESI) $(\mathrm{m} / \mathrm{z}): 476[\mathrm{M}], 477[\mathrm{M}+\mathrm{H}]^{+}, 478[\mathrm{M}+\mathrm{H}]^{++}$.

1-[(5-Methyl-1,3,4-thiadiazol-2-yl)thioacetyl]-3-(2-thienyl)-5-(4-chlorophenyl)-2-pyrazoline (6). Yield: 82\%; M.p. $140.9^{\circ} \mathrm{C}$. IR (KBr) $v_{\max }\left(\mathrm{cm}^{-1}\right)$ : 3103 (aromatic C-H), 2920 (aliphatic C-H asymmetric), 1645 $(\mathrm{C}=\mathrm{O}), 1456,1417(\mathrm{C}=\mathrm{N}$ and $\mathrm{C}=\mathrm{C}), 1398,1325,1219,1072,1029(\mathrm{C}-\mathrm{N}), 840,819(\mathrm{C}-\mathrm{H}$ out of plane deformation). ${ }^{1} \mathrm{H}-\mathrm{NMR}\left(400 \mathrm{MHz}, \delta \mathrm{ppm}, \mathrm{DMSO}-d_{6}\right): 2.66(3 \mathrm{H}, \mathrm{s}), 3.22\left(1 \mathrm{H}, \mathrm{dd}, J_{\mathrm{AX}}=4.80 \mathrm{~Hz}\right.$, $J_{\mathrm{AB}}=18.00 \mathrm{~Hz}$, pyrazoline $\left.\mathrm{C}_{4}-\mathrm{H}_{\mathrm{A}}\right), 3.92\left(1 \mathrm{H}, \mathrm{dd}, J_{\mathrm{BX}}=11.60 \mathrm{~Hz}, J_{\mathrm{BA}}=17.60 \mathrm{~Hz}\right.$, pyrazoline $\left.\mathrm{C}_{4}-\mathrm{H}_{\mathrm{B}}\right)$, $4.54(1 \mathrm{H}, \mathrm{d}, J=16.00 \mathrm{~Hz}$, geminal proton, $\mathrm{CO}-\mathrm{C} \underline{H}), 4.67(1 \mathrm{H}, \mathrm{d}, J=16.00 \mathrm{~Hz}$, geminal proton, $\mathrm{CO}-\mathrm{C} \underline{H}), 5.60\left(1 \mathrm{H}, \mathrm{dd}, J_{\mathrm{AX}}=4.40 \mathrm{~Hz}, J_{\mathrm{BX}}=11.60 \mathrm{~Hz}\right.$, pyrazoline $\left.\mathrm{C}_{5}-\mathrm{Hx}\right), 7.17(1 \mathrm{H}, \mathrm{m}), 7.27(2 \mathrm{H}, \mathrm{d}$, $J=8.40 \mathrm{~Hz}), 7.38(2 \mathrm{H}, \mathrm{d}, J=8.80 \mathrm{~Hz}), 7.50\left(1 \mathrm{H}, \mathrm{dd}, J=0.80 \mathrm{~Hz}, 3.60 \mathrm{~Hz}\right.$, thiophene $\left.\mathrm{C}_{3}-\mathrm{H}\right), 7.79(1 \mathrm{H}$, $\mathrm{dd}, J=1.20 \mathrm{~Hz}, 5.20 \mathrm{~Hz}$, thiophene $\left.\mathrm{C}_{5}-\mathrm{H}\right) .{ }^{13} \mathrm{C}-\mathrm{NMR}(100 \mathrm{MHz}$, DMSO-d 6$) \delta(\mathrm{ppm}): 15.85\left(\mathrm{CH}_{3}\right.$, thiadiazole), $37.33\left(\mathrm{CH}_{2}, \mathrm{~S}-\mathrm{CH}_{2}\right), 43.36\left(\mathrm{CH}_{2}\right.$, pyrazoline $\left.\mathrm{C}_{4}\right), 60.13\left(\mathrm{CH}\right.$, pyrazoline $\left.\mathrm{C}_{5}\right), 128.29(2 \mathrm{CH}$, aromatic), 128.83 (CH, aromatic), 129.29 (2CH, aromatic), $130.93(\mathrm{CH}$, aromatic), 131.83 ( $\mathrm{CH}$, aromatic), $132.63\left(\mathrm{C}\right.$, aromatic), 134.20 (C, aromatic), 141.05 (C, aromatic), 152.08 (C, pyrazoline $\left.\mathrm{C}_{3}\right), 164.40$ (C, aromatic), 164.98 (C, aromatic), $166.37(\mathrm{C}, \mathrm{C}=\mathrm{O})$. Anal. Calcd. for $\mathrm{C}_{18} \mathrm{H}_{15} \mathrm{ClN}_{4} \mathrm{OS}_{3}$ : $\mathrm{C}, 49.70 ; \mathrm{H}, 3.48$; $\mathrm{N}, 12.88$. Found: $\mathrm{C}, 49.72 ; \mathrm{H}, 3.49 ; \mathrm{N}, 12.83$. MS (ESI) (m/z): $434[\mathrm{M}], 435[\mathrm{M}+\mathrm{H}]^{+}, 436[\mathrm{M}+\mathrm{H}]^{++}$, $437[\mathrm{M}+\mathrm{H}]^{+++}$.

1-[(Pyrimidin-2-yl)thioacetyl]-3-(2-thienyl)-5-(4-chlorophenyl)-2-pyrazoline (7). Yield: 78\%; M.p. 126.6 ${ }^{\circ} \mathrm{C}$. IR $(\mathrm{KBr}) v_{\max }\left(\mathrm{cm}^{-1}\right): 3109$ (aromatic C-H), 2929 (aliphatic $\mathrm{C}-\mathrm{H}$ asymmetric), $1653(\mathrm{C}=\mathrm{O})$, 1548, 1448, $1409(\mathrm{C}=\mathrm{N}$ and $\mathrm{C}=\mathrm{C}), 1379,1201,1176,1089,1016(\mathrm{C}-\mathrm{N}), 821(\mathrm{C}-\mathrm{H}$ out of plane deformation). ${ }^{1} \mathrm{H}-\mathrm{NMR}\left(400 \mathrm{MHz}, \delta \mathrm{ppm}, \mathrm{DMSO}-d_{6}\right): 3.19\left(1 \mathrm{H}, \mathrm{dd}, J_{\mathrm{AX}}=4.40 \mathrm{~Hz}, J_{\mathrm{AB}}=18.00 \mathrm{~Hz}\right.$, pyrazoline $\left.\mathrm{C}_{4}-\mathrm{H}_{\mathrm{A}}\right), 3.92\left(1 \mathrm{H}, \mathrm{dd}, J_{\mathrm{BX}}=12.00 \mathrm{~Hz}, J_{\mathrm{BA}}=17.60 \mathrm{~Hz}\right.$, pyrazoline $\left.\mathrm{C}_{4}-\mathrm{H}_{\mathrm{B}}\right), 4.32(1 \mathrm{H}, \mathrm{d}$, $J=16.40 \mathrm{~Hz}$, geminal proton, $\mathrm{CO}-\mathrm{C} \underline{H}), 4.60(1 \mathrm{H}, \mathrm{d}, J=16.00 \mathrm{~Hz}$, geminal proton, CO-C $\underline{H}), 5.61(1 \mathrm{H}$, $\mathrm{dd}, J_{\mathrm{AX}}=4.80 \mathrm{~Hz}, J_{\mathrm{BX}}=11.60 \mathrm{~Hz}$, pyrazoline $\left.\mathrm{C}_{5}-\mathrm{Hx}\right), 7.15-7.18(1 \mathrm{H}, \mathrm{m}), 7.22(1 \mathrm{H}, \mathrm{t}, J=4.80 \mathrm{~Hz}$, $5.20 \mathrm{~Hz}$, pyrimidine), $7.28(2 \mathrm{H}, \mathrm{d}, J=8.00 \mathrm{~Hz}), 7.40(2 \mathrm{H}, \mathrm{d}, J=8.00 \mathrm{~Hz}), 7.47-7.49(1 \mathrm{H}$, m, thiophene $\left.\mathrm{C}_{3}-\mathrm{H}\right), 7.77\left(1 \mathrm{H}, \mathrm{dd}, J=0.80 \mathrm{~Hz}, 4.40 \mathrm{~Hz}\right.$, thiophene $\left.\mathrm{C}_{5}-\mathrm{H}\right), 8.63(2 \mathrm{H}, \mathrm{d}, J=4.80 \mathrm{~Hz}$, pyrimidine). ${ }^{13} \mathrm{C}-\mathrm{NMR}\left(100 \mathrm{MHz}, \mathrm{DMSO}-d_{6}\right) \delta(\mathrm{ppm}): 34.30\left(\mathrm{CH}_{2}, \mathrm{~S}-\mathrm{CH}_{2}\right), 43.34\left(\mathrm{CH}_{2}\right.$, pyrazoline $\left.\mathrm{C}_{4}\right), 60.09(\mathrm{CH}$, pyrazoline $\left.\mathrm{C}_{5}\right), 118.01(\mathrm{CH}$, aromatic), $128.13(2 \mathrm{CH}$, aromatic), $128.81(\mathrm{CH}$, aromatic), $129.27(2 \mathrm{CH}$, aromatic), $130.68(\mathrm{CH}$, aromatic), $131.58(\mathrm{CH}$, aromatic), $132.54(\mathrm{C}$, aromatic), 134.43 (C, aromatic), 141.33 (C, aromatic), 151.47 (C, pyrazoline $\mathrm{C}_{3}$ ), 158.42 (2CH, aromatic), 165.28 (C, C=O), 170.99 (C, aromatic). Anal. Calcd. for $\mathrm{C}_{19} \mathrm{H}_{15} \mathrm{ClN}_{4} \mathrm{OS}_{2}$ : C, 55.00; H, 3.64; N, 13.50. Found: C, 55.11; H, 3.51; N, 13.43. $\mathrm{MS}(\mathrm{ESI})(\mathrm{m} / \mathrm{z}): 414[\mathrm{M}], 415[\mathrm{M}+\mathrm{H}]^{+}, 416[\mathrm{M}+\mathrm{H}]^{++}$. 
1-[(5-Phenyl-1,3,4-oxadiazol-2-yl)thioacetyl]-3-(2-thienyl)-5-(4-chlorophenyl)-2-pyrazoline (8). Yield: 74\%; M.p. $162.3{ }^{\circ} \mathrm{C}$. IR (KBr) $v_{\max }\left(\mathrm{cm}^{-1}\right)$ : 3107 (aromatic C-H), 2983 (aliphatic C-H asymmetric), 1670 $(\mathrm{C}=\mathrm{O}), 1465,1450,1408(\mathrm{C}=\mathrm{N}$ and $\mathrm{C}=\mathrm{C}), 1238,1197,1068,1012(\mathrm{C}-\mathrm{N}), 827(\mathrm{C}-\mathrm{H}$ out of plane deformation). ${ }^{1} \mathrm{H}-\mathrm{NMR}\left(400 \mathrm{MHz}, \delta \mathrm{ppm}, \mathrm{DMSO}-d_{6}\right): 3.23\left(1 \mathrm{H}, \mathrm{dd}, J_{\mathrm{AX}}=4.40 \mathrm{~Hz}, J_{\mathrm{AB}}=18.00 \mathrm{~Hz}\right.$, pyrazoline $\left.\mathrm{C}_{4}-\mathrm{H}_{\mathrm{A}}\right), 3.93\left(1 \mathrm{H}, \mathrm{dd}, J_{\mathrm{BX}}=11.60 \mathrm{~Hz}, J_{\mathrm{BA}}=18.00 \mathrm{~Hz}\right.$, pyrazoline $\left.\mathrm{C}_{4}-\mathrm{H}_{\mathrm{B}}\right), 4.63(1 \mathrm{H}, \mathrm{d}$, $J=16.00 \mathrm{~Hz}$, geminal proton, $\mathrm{CO}-\mathrm{C} \underline{H}), 4.77(1 \mathrm{H}, \mathrm{d}, J=16.00 \mathrm{~Hz}$, geminal proton, CO-C $\underline{H}), 5.62(1 \mathrm{H}$, $\mathrm{dd}, J_{\mathrm{AX}}=4.80 \mathrm{~Hz}, J_{\mathrm{BX}}=11.60 \mathrm{~Hz}$, pyrazoline $\left.\mathrm{C}_{5}-\mathrm{Hx}\right), 7.16-7.19(1 \mathrm{H}, \mathrm{m}), 7.26(2 \mathrm{H}, \mathrm{d}, J=8.40 \mathrm{~Hz})$, $7.34(2 \mathrm{H}, \mathrm{d}, J=8.80 \mathrm{~Hz}), 7.51-7.64(4 \mathrm{H}, \mathrm{m}), 7.78-7.80\left(1 \mathrm{H}, \mathrm{m}\right.$, thiophene $\left.\mathrm{C}_{5}-\mathrm{H}\right), 7.92-7.95$ (2H, m). ${ }^{13} \mathrm{C}-\mathrm{NMR}\left(100 \mathrm{MHz}, \mathrm{DMSO}-d_{6}\right) \delta(\mathrm{ppm}): 36.11\left(\mathrm{CH}_{2}, \mathrm{~S}-\mathrm{CH}_{2}\right), 43.40\left(\mathrm{CH}_{2}\right.$, pyrazoline $\left.\mathrm{C}_{4}\right), 60.19(\mathrm{CH}$, pyrazoline $\left.\mathrm{C}_{5}\right), 123.66$ (C, aromatic), $127.03(2 \mathrm{CH}$, aromatic), $128.24(2 \mathrm{CH}$, aromatic), $128.85(\mathrm{CH}$, aromatic), $129.29(2 \mathrm{CH}$, aromatic), $130.07(2 \mathrm{CH}$, aromatic), $131.00(\mathrm{CH}$, aromatic), $131.95(\mathrm{CH}$, aromatic), 132.66 (C, aromatic), 132.69 (CH, aromatic), 134.12 (C, aromatic), 140.99 (C, aromatic), 152.35 (C, pyrazoline $\mathrm{C}_{3}$ ), 164.02 (C, aromatic), 164.13 (C, aromatic), $165.77(\mathrm{C}, \mathrm{C}=\mathrm{O})$. Anal. Calcd. for $\mathrm{C}_{23} \mathrm{H}_{17} \mathrm{ClN}_{4} \mathrm{O}_{2} \mathrm{~S}_{2}$ : C, 57.43; H, 3.56; N, 11.65. Found: C, 57.47; H, 3.55; N, 11.61. MS (ESI) (m/z): $481[\mathrm{M}+\mathrm{H}]^{+}$.

1-[(5-(Pyridin-3-yl)-1,3,4-oxadiazol-2-yl)thioacetyl]-3-(2-thienyl)-5-(4-chlorophenyl)-2-pyrazoline (9). Yield: 70\%; M.p. $156.9^{\circ} \mathrm{C}$. IR (KBr) $v_{\max }\left(\mathrm{cm}^{-1}\right)$ : 3080 (aromatic C-H), 2981 (aliphatic C-H asymmetric), $1668(\mathrm{C}=\mathrm{O}), 1456,1417(\mathrm{C}=\mathrm{N}$ and $\mathrm{C}=\mathrm{C}), 1199,1076,1016(\mathrm{C}-\mathrm{N}), 833(\mathrm{C}-\mathrm{H}$ out of plane deformation). ${ }^{1} \mathrm{H}-\mathrm{NMR}\left(400 \mathrm{MHz}, \delta \mathrm{ppm}, \mathrm{DMSO}-d_{6}\right): 3.24\left(1 \mathrm{H}, \mathrm{dd}, J_{\mathrm{AX}}=4.80 \mathrm{~Hz}, J_{\mathrm{AB}}=18.00 \mathrm{~Hz}\right.$, pyrazoline $\left.\mathrm{C}_{4}-\mathrm{H}_{\mathrm{A}}\right), 3.94\left(1 \mathrm{H}, \mathrm{dd}, J_{\mathrm{BX}}=11.60 \mathrm{~Hz}, J_{\mathrm{BA}}=18.40 \mathrm{~Hz}\right.$, pyrazoline $\left.\mathrm{C}_{4}-\mathrm{HB}\right), 4.65(1 \mathrm{H}, \mathrm{d}, J=16.00 \mathrm{~Hz}$, geminal proton, $\mathrm{CO}-\mathrm{C} \underline{H}), 4.79(1 \mathrm{H}, \mathrm{d}, J=16.00 \mathrm{~Hz}$, geminal proton, CO-C $\underline{H}), 5.63\left(1 \mathrm{H}, \mathrm{dd}, J_{\mathrm{AX}}=4.80 \mathrm{~Hz}\right.$, $J_{\mathrm{BX}}=12.00 \mathrm{~Hz}$, pyrazoline $\left.\mathrm{C}_{5}-\mathrm{Hx}\right), 7.16-7.18(1 \mathrm{H}, \mathrm{m}), 7.28(2 \mathrm{H}, \mathrm{d}, J=8.40 \mathrm{~Hz}), 7.35(2 \mathrm{H}, \mathrm{d}, J=8.40 \mathrm{~Hz})$, $7.50\left(1 \mathrm{H}, \mathrm{dd}, J=1.20 \mathrm{~Hz}, 4.00 \mathrm{~Hz}\right.$, thiophene $\left.\mathrm{C}_{3}-\mathrm{H}\right), 7.58-7.62\left(1 \mathrm{H}, \mathrm{m}\right.$, pyridine $\left.\mathrm{C}_{5}-\mathrm{H}\right), 7.78(1 \mathrm{H}, \mathrm{dd}$, $J=0.80 \mathrm{~Hz}, 4.80 \mathrm{~Hz}$, thiophene $\left.\mathrm{C}_{5}-\mathrm{H}\right), 8.29-8.32(1 \mathrm{H}, \mathrm{m}$, pyridine), $8.79(1 \mathrm{H}, \mathrm{dd}, J=1.60 \mathrm{~Hz}, 4.80 \mathrm{~Hz}$, pyridine), $9.12\left(1 \mathrm{H}, \mathrm{d}, J=1.60 \mathrm{~Hz}\right.$, pyridine). ${ }^{13} \mathrm{C}-\mathrm{NMR}\left(100 \mathrm{MHz}, \mathrm{DMSO}-d_{6}\right) \delta(\mathrm{ppm}): 36.28\left(\mathrm{CH}_{2}\right.$, S-CH$), ~ 43.42\left(\mathrm{CH}_{2}\right.$, pyrazoline $\left.\mathrm{C}_{4}\right), 60.23\left(\mathrm{CH}\right.$, pyrazoline $\left.\mathrm{C}_{5}\right), 120.31(\mathrm{CH}$, aromatic $), 124.98(\mathrm{C}$, aromatic), $128.27(2 \mathrm{CH}$, aromatic), $128.85(\mathrm{CH}$, aromatic), $129.31(2 \mathrm{CH}$, aromatic), $130.99(\mathrm{CH}$, aromatic), $131.93(\mathrm{CH}$, aromatic), $132.69(\mathrm{CH}$, aromatic), 134.12 (C, aromatic), $134.64(\mathrm{C}$, aromatic), 140.99 (C, aromatic), $147.74\left(\mathrm{CH}\right.$, aromatic), 152.37 (C, pyrazoline $\left.\mathrm{C}_{3}\right), 153.16(\mathrm{CH}$, aromatic), 164.04 (C, aromatic), 164.08 (C, aromatic), $164.76(\mathrm{C}, \mathrm{C}=\mathrm{O})$. Anal. Calcd. for $\mathrm{C}_{22} \mathrm{H}_{16} \mathrm{ClN}_{5} \mathrm{O}_{2} \mathrm{~S}_{2}$ : C, 54.82; $\mathrm{H}, 3.35$; N, 14.53. Found: C, 54.83; H, 3.33; N, 14.60. MS (ESI) (m/z): $481[\mathrm{M}], 482[\mathrm{M}+\mathrm{H}]^{+}, 483[\mathrm{M}+\mathrm{H}]^{++}$.

1-[(5-(4-Chlorophenyl)-1,3,4-oxadiazol-2-yl)thioacetyl]-3-(2-thienyl)-5-(4-chlorophenyl)-2-pyrazoline (10). Yield: $77 \%$; M.p. $176.5{ }^{\circ} \mathrm{C}$. IR (KBr) $v_{\max }\left(\mathrm{cm}^{-1}\right)$ : 3099 (aromatic C-H), 2981 (aliphatic C-H asymmetric), $1643(\mathrm{C}=\mathrm{O}), 1463,1417(\mathrm{C}=\mathrm{N}$ and $\mathrm{C}=\mathrm{C}), 1392,1188,1174,1082,1008(\mathrm{C}-\mathrm{N}), 952,840$, 819 (C-H out of plane deformation). ${ }^{1} \mathrm{H}-\mathrm{NMR}\left(400 \mathrm{MHz}, \delta \mathrm{ppm}, \mathrm{DMSO}-d_{6}\right): 3.23\left(1 \mathrm{H}, \mathrm{dd}, J_{\mathrm{AX}}=4.80 \mathrm{~Hz}\right.$, $J_{\mathrm{AB}}=18.40 \mathrm{~Hz}$, pyrazoline $\left.\mathrm{C}_{4}-\mathrm{H}_{\mathrm{A}}\right), 3.93\left(1 \mathrm{H}, \mathrm{dd}, J_{\mathrm{BX}}=11.60 \mathrm{~Hz}, J_{\mathrm{BA}}=18.00 \mathrm{~Hz}\right.$, pyrazoline $\left.\mathrm{C}_{4}-\mathrm{H}_{\mathrm{B}}\right)$, $4.62(1 \mathrm{H}, \mathrm{d}, J=16.00 \mathrm{~Hz}$, geminal proton, $\mathrm{CO}-\mathrm{C} \underline{H}), 4.75(1 \mathrm{H}, \mathrm{d}, J=16.00 \mathrm{~Hz}$, geminal proton, $\mathrm{CO}-\mathrm{C} \underline{H}), 5.62\left(1 \mathrm{H}, \mathrm{dd}, J_{\mathrm{AX}}=4.80 \mathrm{~Hz}, J_{\mathrm{BX}}=11.20 \mathrm{~Hz}\right.$, pyrazoline $\left.\mathrm{C}_{5}-\mathrm{Hx}\right), 7.17(1 \mathrm{H}, \mathrm{dd}, J=3.60 \mathrm{~Hz}$, $5.20 \mathrm{~Hz}$ thiophene $\left.\mathrm{C}_{4}-\mathrm{H}\right), 7.27(2 \mathrm{H}, \mathrm{d}, J=8.40 \mathrm{~Hz}), 7.35(2 \mathrm{H}, \mathrm{d}, J=8.40 \mathrm{~Hz}), 7.50(1 \mathrm{H}, \mathrm{dd}, J=0.80 \mathrm{~Hz}$, $3.60 \mathrm{~Hz}$, thiophene $\left.\mathrm{C}_{3}-\mathrm{H}\right), 7.62(2 \mathrm{H}, \mathrm{d}, J=8.80 \mathrm{~Hz}), 7.77(1 \mathrm{H}, \mathrm{dd}, J=0.80 \mathrm{~Hz}, 5.20 \mathrm{~Hz}$, thiophene 
$\left.\mathrm{C}_{5}-\mathrm{H}\right), 7.93(2 \mathrm{H}, \mathrm{d}, J=8.40 \mathrm{~Hz}) \cdot{ }^{13} \mathrm{C}-\mathrm{NMR}\left(100 \mathrm{MHz}, \mathrm{DMSO}-\mathrm{d}_{6}\right) \delta(\mathrm{ppm}): 36.16\left(\mathrm{CH}_{2}, \mathrm{~S}-\mathrm{CH}_{2}\right), 43.41$ $\left(\mathrm{CH}_{2}\right.$, pyrazoline $\left.\mathrm{C}_{4}\right), 60.23\left(\mathrm{CH}\right.$, pyrazoline $\left.\mathrm{C}_{5}\right), 122.55$ (C, aromatic), 128.25 (2CH, aromatic), 128.81 (3CH, aromatic), 129.29 (2CH, aromatic), $130.21(2 \mathrm{CH}$, aromatic), $130.93(\mathrm{CH}$, aromatic), $131.82(\mathrm{CH}$, aromatic), 132.71 (C, aromatic), 134.15 (C, aromatic), 137.42 (C, aromatic), 140.96 (C, aromatic), 152.32 $\left(\mathrm{C}\right.$, pyrazoline $\left.\mathrm{C}_{3}\right), 164.12$ (C, aromatic), 164.30 (C, aromatic), $165.05(\mathrm{C}, \mathrm{C}=\mathrm{O})$. Anal. Calcd. for $\mathrm{C}_{23} \mathrm{H}_{16} \mathrm{Cl}_{2} \mathrm{~N}_{4} \mathrm{O}_{2} \mathrm{~S}_{2}$ : C, 53.59; H, 3.13; N, 10.87. Found: C, 53.48; H, 3.17; N, 10.75. MS (ESI) (m/z): 515 $[\mathrm{M}], 516[\mathrm{M}+\mathrm{H}]^{+}, 517[\mathrm{M}+\mathrm{H}]^{++}$.

1-[(5-(4-Methylphenyl)-1,3,4-oxadiazol-2-yl)thioacetyl]-3-(2-thienyl)-5-(4-chlorophenyl)-2-pyrazoline (11). Yield: 79\%; M.p. $194.0{ }^{\circ} \mathrm{C}$. IR (KBr) $v_{\max }\left(\mathrm{cm}^{-1}\right)$ : 3078 (aromatic C-H), 2926 (aliphatic C-H asymmetric), $1668(\mathrm{C}=\mathrm{O}), 1469,1450,1409(\mathrm{C}=\mathrm{N}$ and $\mathrm{C}=\mathrm{C}), 1197,1072(\mathrm{C}-\mathrm{N}), 829(\mathrm{C}-\mathrm{H}$ out of plane deformation). ${ }^{1} \mathrm{H}-\mathrm{NMR}\left(400 \mathrm{MHz}, \delta \mathrm{ppm}, \mathrm{DMSO}-d_{6}\right): 2.38\left(3 \mathrm{H}, \mathrm{s}, \mathrm{CH}_{3}\right), 3.22\left(1 \mathrm{H}, \mathrm{dd}, J_{\mathrm{AX}}=4.80 \mathrm{~Hz}\right.$, $J_{\mathrm{AB}}=18.00 \mathrm{~Hz}$, pyrazoline $\left.\mathrm{C}_{4}-\mathrm{H}_{\mathrm{A}}\right), 3.93\left(1 \mathrm{H}, \mathrm{dd}, J_{\mathrm{BX}}=11.60 \mathrm{~Hz}, J_{\mathrm{BA}}=18.00 \mathrm{~Hz}\right.$, pyrazoline $\left.\mathrm{C}_{4}-\mathrm{H}_{\mathrm{B}}\right)$, $4.60(1 \mathrm{H}, \mathrm{d}, J=15.60 \mathrm{~Hz}$, geminal proton, $\mathrm{CO}-\mathrm{C} \underline{H}), 4.73(1 \mathrm{H}, \mathrm{d}, J=15.60 \mathrm{~Hz}$, geminal proton, CO-C $\underline{H})$, $5.61\left(1 \mathrm{H}, \mathrm{dd}, J_{\mathrm{AX}}=4.80 \mathrm{~Hz}, J_{\mathrm{BX}}=11.20 \mathrm{~Hz}\right.$, pyrazoline $\left.\mathrm{C}_{5}-\mathrm{Hx}\right), 7.15-7.18\left(1 \mathrm{H}, \mathrm{m}\right.$, thiophene $\left.\mathrm{C}_{4}-\mathrm{H}\right)$, $7.26(2 \mathrm{H}, \mathrm{d}, J=8.80 \mathrm{~Hz}), 7.33(2 \mathrm{H}, \mathrm{d}, J=8.80 \mathrm{~Hz}), 7.36(2 \mathrm{H}, \mathrm{d}, J=8.40 \mathrm{~Hz}), 7.49(1 \mathrm{H}, \mathrm{m}$, thiophene $\left.\mathrm{C}_{3}-\mathrm{H}\right), 7.77\left(1 \mathrm{H}, \mathrm{d}, J=4.80 \mathrm{~Hz}\right.$, thiophene $\left.\mathrm{C}_{5}-\mathrm{H}\right), 7.81(2 \mathrm{H}, \mathrm{d}, J=8.00 \mathrm{~Hz}) .{ }^{13} \mathrm{C}-\mathrm{NMR}(100 \mathrm{MHz}$, DMSO-d6) $\delta$ (ppm): $21.80\left(\mathrm{CH}_{3}\right), 36.09\left(\mathrm{CH}_{2}, \mathrm{~S}-\mathrm{CH}_{2}\right), 43.41\left(\mathrm{CH}_{2}\right.$, pyrazoline $\left.\mathrm{C}_{4}\right), 60.22(\mathrm{CH}$, pyrazoline $\left.\mathrm{C}_{5}\right), 120.97$ (C, aromatic), $127.00(2 \mathrm{CH}$, aromatic), $128.24(2 \mathrm{CH}$, aromatic), 128.81 ( $\mathrm{CH}$, aromatic), $129.29(2 \mathrm{CH}$, aromatic), 130.59 (2CH, aromatic), $130.93(\mathrm{CH}$, aromatic), $131.82(\mathrm{CH}$, aromatic), 132.69 (C, aromatic), 134.16 (C, aromatic), 140.98 (C, aromatic), 142.84 (C, aromatic), 152.29 (C, pyrazoline $\mathrm{C}_{3}$ ), 163.60 (C, aromatic), 164.17 (C, aromatic), $165.91\left(\mathrm{C}, \mathrm{C}=\mathrm{O}\right.$ ). Anal. Calcd. for $\mathrm{C}_{24} \mathrm{H}_{19} \mathrm{ClN}_{4} \mathrm{O}_{2} \mathrm{~S}_{2}$ : $\mathrm{C}$, 58.23; H, 3.87; N, 11.32. Found: C, 58.19; H, 3.92; N, 11.25. MS (ESI) (m/z): 495 [M], 496 [M + H] , $497[\mathrm{M}+\mathrm{H}]^{++}$.

1-[(5-(4-Methoxyphenyl)-1,3,4-oxadiazol-2-yl)thioacetyl]-3-(2-thienyl)-5-(4-chlorophenyl)-2-pyrazoline (12). Yield: $72 \%$; M.p. $146.8{ }^{\circ}$ C. IR (KBr) $v_{\max }\left(\mathrm{cm}^{-1}\right)$ : 3082 (aromatic C-H), 2933 (aliphatic C-H asymmetric), $1670(\mathrm{C}=\mathrm{O}), 1504,1477,1452,1413(\mathrm{C}=\mathrm{N}$ and $\mathrm{C}=\mathrm{C}), 1251,1178,1026(\mathrm{C}-\mathrm{N}), 840(\mathrm{C}-\mathrm{H}$ out of plane deformation). ${ }^{1} \mathrm{H}-\mathrm{NMR}\left(400 \mathrm{MHz}, \delta \mathrm{ppm}, \mathrm{DMSO}-d_{6}\right): 3.21\left(1 \mathrm{H}, \mathrm{dd}, J_{\mathrm{AX}}=4.80 \mathrm{~Hz}\right.$, $J_{A B}=18.00 \mathrm{~Hz}$, pyrazoline $\left.\mathrm{C}_{4}-\mathrm{H}_{\mathrm{A}}\right), 3.84\left(3 \mathrm{H}, \mathrm{s}, \mathrm{OCH}_{3}\right), 3.92\left(1 \mathrm{H}, \mathrm{dd}, J_{\mathrm{BX}}=11.60 \mathrm{~Hz}, J_{\mathrm{BA}}=17.60 \mathrm{~Hz}\right.$, pyrazoline $\left.\mathrm{C}_{4}-\mathrm{H}_{\mathrm{B}}\right), 4.57(1 \mathrm{H}, \mathrm{d}, J=16.00 \mathrm{~Hz}$, geminal proton, CO-Cㅡㅡ), $4.71(1 \mathrm{H}, \mathrm{d}, J=15.60 \mathrm{~Hz}$, geminal proton, CO-C $\underline{H}), 5.61\left(1 \mathrm{H}, \mathrm{dd}, J_{\mathrm{AX}}=4.80 \mathrm{~Hz}, J_{\mathrm{BX}}=11.60 \mathrm{~Hz}\right.$, pyrazoline $\left.\mathrm{C}_{5}-\mathrm{Hx}\right), 7.08(2 \mathrm{H}, \mathrm{d}$, $J=9.20 \mathrm{~Hz}), 7.16\left(1 \mathrm{H}, J=3.60 \mathrm{~Hz}, 4.80 \mathrm{~Hz}\right.$, thiophene $\left.\mathrm{C}_{4}-\mathrm{H}\right), 7.25(2 \mathrm{H}, \mathrm{d}, J=8.80 \mathrm{~Hz}), 7.34(2 \mathrm{H}, \mathrm{d}$, $J=8.80 \mathrm{~Hz}), 7.50\left(1 \mathrm{H}, \mathrm{dd}, J=1.20 \mathrm{~Hz}, 4.00 \mathrm{~Hz}\right.$, thiophene $\left.\mathrm{C}_{3}-\mathrm{H}\right), 7.77(1 \mathrm{H}, \mathrm{dd}, J=1.20 \mathrm{~Hz}, 4.80 \mathrm{~Hz}$, thiophene $\left.\mathrm{C}_{5}-\mathrm{H}\right), 7.86(2 \mathrm{H}, \mathrm{d}, J=8.80 \mathrm{~Hz}) .{ }^{13} \mathrm{C}-\mathrm{NMR}\left(100 \mathrm{MHz}, \mathrm{DMSO}-d_{6}\right) \delta(\mathrm{ppm}): 36.03\left(\mathrm{CH}_{2}\right.$, S-CH$), 43.42\left(\mathrm{CH}_{2}\right.$, pyrazoline $\left.\mathrm{C}_{4}\right), 56.23\left(\mathrm{CH}_{3}\right.$, methoxy), $60.24\left(\mathrm{CH}\right.$, pyrazoline $\left.\mathrm{C}_{5}\right), 115.54(2 \mathrm{CH}$, aromatic), $116.10(\mathrm{C}$, aromatic), $128.24(2 \mathrm{CH}$, aromatic), $128.80(\mathrm{CH}$, aromatic), $128.92(2 \mathrm{CH}$, aromatic), $129.29(2 \mathrm{CH}$, aromatic), $130.89(\mathrm{CH}$, aromatic), $131.74(\mathrm{CH}$, aromatic), 132.70 (C, aromatic), 134.19 (C, aromatic), 140.98 (C, aromatic), 152.25 (C, pyrazoline $\mathrm{C}_{3}$ ), 162.77 (C, aromatic), 163.11 (C, aromatic), 164.26 (C, aromatic), $165.80(\mathrm{C}, \mathrm{C}=\mathrm{O})$. Anal. Calcd. for $\mathrm{C}_{24} \mathrm{H}_{19} \mathrm{ClN}_{4} \mathrm{O}_{3} \mathrm{~S}_{2}$ : $\mathrm{C}, 56.41 ; \mathrm{H}, 3.75$; N, 10.96. Found: C, 56.39; H, 3.73; N, 10.98. MS (ESI) (m/z): $511[\mathrm{M}], 512[\mathrm{M}+\mathrm{H}]^{+}, 513[\mathrm{M}+\mathrm{H}]^{++}$. 


\subsection{Biochemistry}

\subsubsection{Cell Culture and Drug Treatment}

U251 and U87 human glioblastoma cells were incubated in Dulbecco's-modified Eagle's medium (DMEM) (Wako Pure Chemical Industries, Osaka, Japan) supplemented with 10\% fetal bovine serum (FBS) (Equitech-Bio, Kerrville, TX, USA). AsPC-1 human pancreas adenocarcinoma and Jurkat human leukemic T-cells were incubated RPMI 1640 (Wako Pure Chemical Industries), supplemented with 10\% FBS. Peripheral blood mononuclear cells (PBMC) (Precision Bioservices, Frederick, MD, USA) were incubated RPMI 1640 and supplemented with 10\% human serum AB (HS) (Gemini, Woodland, CA, USA). All media were supplemented with $89 \mu \mathrm{g} / \mathrm{mL}$ streptomycin (Meiji Seika Pharma, Tokyo, Japan) and cells were incubated at $37{ }^{\circ} \mathrm{C}$ in a humidified atmosphere of $95 \%$ air and $5 \% \mathrm{CO}_{2}$. Growing cells were plated at $1 \times 10^{5}$ cells $/ \mathrm{mL}$ into 24-well microtiter tissue culture plates (Iwaki brand Asahi Glass Co., Chiba, Japan) and incubated for $24 \mathrm{~h}$ before the addition of the drugs (the optimal cell number for cytotoxicity assays was determined in preliminary experiments). Stock solutions ( $1 \mathrm{mM}, 5 \mathrm{mM}, 10 \mathrm{mM}, 20 \mathrm{mM}$, and $50 \mathrm{mM}$ ) of compounds and cisplatin (Sigma-Aldrich, St. Louis, MO, USA) were prepared in dimethyl sulfoxide (DMSO; Wako Pure Chemical Industries) and in dimethylformamide (DMF; Wako Pure Chemical Industries) respectively, then were added to fresh culture medium. The concentration of DMSO and DMF in the final culture medium was $1 \%$.

\subsubsection{MTT Assay for Cytotoxicity of Compounds}

The level of cellular reduction of 3-(4,5-dimethylthiazol-2-yl)-2,5-diphenyltetrazolium bromide (MTT) (Dojindo Molecular Technologies, Kumamoto, Japan) was quantified as previously described in the literature with small modifications [38]. The tested compounds were incubated with cells to give a final concentration in the range $50-500 \mu \mathrm{M}$ for $24 \mathrm{~h}$. At the end of this period, MTT was added to cells in culture to give a final concentration of $0.275 \mathrm{mg} / \mathrm{mL}$ and incubated further for $4 \mathrm{~h}$ at $37{ }^{\circ} \mathrm{C}$. The medium was removed and the formazan crystals were solubilized by addition of $100 \mu \mathrm{L}$ DMSO to each well. After the solubilized crystals were diluted (1:10) with DMSO, $100 \mu \mathrm{L}$ was transferred to wells of 96-well microtiter plates (Iwaki brand Asahi Glass Co.) and the absorbance at $550 \mathrm{~nm}$ was measured using a microplate spectrophotometer Infinitive M1000 (Tecan, Groding, Austria). Every concentration was repeated in three wells and $\mathrm{IC}_{50}$ values were defined as the drug concentrations which reduced absorbance to $50 \%$ of control values.

\subsubsection{Detection of Apoptotic and Necrotic Cells}

U251 cells were incubated with compound $\mathbf{1 1}$ at $\mathrm{IC}_{50}$ concentration for $3 \mathrm{~h}$ and $24 \mathrm{~h}$. Then, apoptotic/necrotic/healthy cells detection kit protocol was applied according to the manufacturer's instruction manual (PromoKine, Heidelberg, Germany) [39,40]. After the cells were washed twice with $1 \times$ binding buffer, a staining solution containing $50 \mu \mathrm{L}$ of $1 \times$ binding buffer, $2 \mu \mathrm{L}$ of FTIC-Annexin V solution, $2 \mu \mathrm{L}$ of ethidium homodimer III solution and $2 \mu \mathrm{L}$ of Hoechst 33342 solution was added and the cells were incubated for $15 \mathrm{~min}$ at RT, protected from light. Cells were washed with $1 \times$ binding 
buffer and analyzed by all-in-one fluorescence microscope Biorevo Fluorescence BZ-9000 (Keyence, Osaka, Japan).

\subsubsection{DNA Cleavage Assay}

The DNA cleavage activities of the compounds were studied using supercoiled pUC19 DNA and analyzed by agarose (Takara, Kyoto, Japan) gel electrophoresis Mupid-2x (Mupid, Tokyo, Japan). pUC19 DNA $(2 \mu \mathrm{g})$ was treated with compounds in water and Tris/boric acid (Nacalai Tesque, Kyoto, Japan) buffer $(10 \mathrm{mM}, \mathrm{pH} 8.5)$ in the presence and absence of iron (II) sulfate heptahydrate $\left(\mathrm{FeSO}_{4} \cdot 7 \mathrm{H}_{2} \mathrm{O} ; 30 \mu \mathrm{M}\right)$ (Wako Pure Chemical Industries), hydrogen peroxide $\left(\mathrm{H}_{2} \mathrm{O}_{2} ; 30 \mu \mathrm{M}\right)$ (Tokyo Chemical Industry Co., Tokyo, Japan) and ascorbic acid (30 $\mu \mathrm{M})$ (Tokyo Chemical Industry Co.) as an activator. The reaction mixture was incubated at $37^{\circ} \mathrm{C}$ for $1.5 \mathrm{~h}$ before the addition of EDTA (Dojindo Molecular Technologies) and loading buffer (Takara, Kyoto, Japan). Agarose gel electrophoresis of pUC 19 DNA was performed at $100 \mathrm{~V}$ for $40 \mathrm{~min}$ in 1\% slab gels containing ethidium bromide (Wako Pure Chemical Industries) in Tris/Boronic acid/EDTA buffer. DNA was visualized by photographing the fluorescence of intercalated ethidium bromide under a UV illuminator (Nippon Genetics Co., Tokyo, Japan).

\section{Conclusions}

In the present paper, new pyrazoline derivatives were synthesized and investigated for their antiproliferative effects on AsPC-1 human pancreatic adenocarcinoma, U87, and U251 human glioblastoma cell lines. Detailed investigation of compound 11 against AsPC-1, U87, U251 cell lines and tumor selectivity of this compound on blood cells (PBMC and Jurkat cells) were also carried out. Among these compounds, compound $\mathbf{1 1}$ was the most effective anticancer agent against AsPC-1 and U251 cancer cell lines and exhibited significant tumor selectivity. Therefore, compound $\mathbf{1 1}$ was chosen for apoptosis/necrosis evaluation and DNA-cleavage analysis in U251 cells. Compound 11-treated U251 cells showed apoptotic activity at low concentration $(1.5 \mu \mathrm{M})$. Interestingly, DNA-cleaving efficiency of this ligand was more significant than cisplatin. This outcome pointed out the relationship between the DNA cleavage and the cell death.

In the view of this study, further research can be carried out on the development of new effective anticancer agents by the modification of compound $\mathbf{1 1}$.

\section{Acknowledgments}

This study was supported by Anadolu University Scientific Research Projects Commission under the grant no: $1505 \mathrm{~S} 371$.

\section{Author Contributions}

A.Ö., M.D.A. and M.K. designed the research; M.D.A. and M.K. performed the synthetic work, M.O., M.F. and H.İ.Ç. were responsible for the direction of the biological research, H.İ.Ç. and R.K. performed the anticancer activity. A.Ö. was also responsible for the correspondence of the manuscript, whereas M.D.A. and H.İ.Ç. mainly wrote the manuscript. All authors discussed, edited and approved the final version. 


\section{Conflicts of Interest}

The authors declare no conflict of interest.

\section{References}

1. Mathur, G.; Nain, S.; Sharma, P.K. Cancer: An Overview. Acad. J. Cancer Res. 2015, 8, doi:10.5829/idosi.ajcr.2015.8.1.9336.

2. Nepali, K.; Sharma, S.; Sharma, M.; Bedi, P.M.S.; Dhar, K.L. Rational approaches, design strategies, structure activity relationship and mechanistic insights for anticancer hybrids. Eur. J. Med. Chem. 2014, 77, 422-487.

3. Rebucci, M.; Michiels, C. Molecular aspects of cancer cell resistance to chemotherapy. Biochem. Pharmacol. 2013, 85, 1219-1226.

4. Nussbaumer, S.; Bonnabry, P.; Veuthey, J.-L.; Fleury-Souverain, S. Analysis of anticancer drugs: A review. Talanta 2011, 85, 2265-2289.

5. Kumar, S.; Bawa, S.; Drabu, S.; Kumar, R.; Gupta, H. Biological Activities of Pyrazoline Derivatives-A Recent Development. Recent Pat. Anti-Infect. Drug Discov. 2009, 4, 154-163.

6. Shaaban, M.R.; Mayhoub, A.S.; Farag, A.M. Recent advances in the therapeutic applications of pyrazolines. Expert Opin. Ther. Pat. 2012, 22, 253-291.

7. Marella, A.; Ali, R.; Alam, T.; Saha, R.; Tanwar, O.; Akhter, M.; Shaquiquzzaman, M.; Alam, M.M. Pyrazolines: A biological review. Mini-Rev. Med. Chem. 2013, 13, 921-931.

8. Alex, J.M.; Kumar, R. 4,5-Dihydro-1H-pyrazole: An indispensable scaffold. J. Enzyme Inhib. Med. Chem. 2014, 29, 427-442.

9. Havrylyuk, D.; Zimenkovsky, B.; Vasylenko, O.; Zaprutko, L.; Gzella, A.; Lesyk, R. Synthesis of novel thiazolone-based compounds containing pyrazoline moiety and evaluation of their anticancer activity. Eur. J. Med. Chem. 2009, 44, 1396-1404.

10. Shaharyar, M.; Abdullah, M.M.; Bakht, M.A.; Majeed, J. Pyrazoline bearing benzimidazoles: Search for anticancer agent. Eur. J. Med. Chem. 2010, 45, 114-119.

11. Congiu, C.; Onnis, V.; Vesci, L.; Castorina, M.; Pisano, C. Synthesis and in vitro antitumor activity of new 4,5-dihydropyrazole derivatives. Bioorg. Med. Chem. 2010, 18, 6238-6248.

12. Al-Abdullah, E.S. Synthesis and Anticancer Activity of Some Novel Tetralin-6-yl-pyrazoline, 2-Thioxopyrimidine, 2-Oxopyridine, 2-Thioxo-pyridine and 2-Iminopyridine Derivatives. Molecules 2011, 16, 3410-3419.

13. Bano, S.; Javed, K.; Ahmad, S.; Rathish, I.G.; Singh, S.; Alam M.S. Synthesis and biological evaluation of some new 2-pyrazolines bearing benzene sulfonamide moiety as potential anti-inflammatory and anti-cancer agents. Eur. J. Med. Chem. 2011, 46, 5763-5768.

14. Bashir, R.; Ovais, S.; Yaseen, S.; Hamid, H.; Alam, M.S.; Samim, M.; Singh, S.; Javed, K. Synthesis of some new 1,3,5-trisubstituted pyrazolines bearing benzene sulfonamide as anticancer and anti-inflammatory agents. Bioorg. Med. Chem. Lett. 2011, 21, 4301-4305.

15. Amin, K.M.; Eissa, A.A.M.; Abou-Seri, S.M.; Awadallah, F.M.; Hassan, G.S. Synthesis and biological evaluation of novel coumarine-pyrazoline hybrids endowed with phenylsulfonyl moiety as antitumor agents. Eur. J. Med. Chem. 2013, 60, 187-198. 
16. Montoya, A.; Quiroga, J.; Abonia, R.; Nogueras, M.; Cobo, J.; Insuasty, B. Synthesis and in Vitro Antitumor Activity of a Novel Series of 2-Pyrazoline Derivatives Bearing the 4-Aryloxy-7chloroquinoline Fragment. Molecules 2014, 19, 18656-18675.

17. Insuasty, B.; Montoya, A.; Becerra, D.; Quiroga, J.; Abonia, R.; Robledo, S.; Darío Vélez, I.; Upegui, Y.; Nogueras, M.; Cobo, J. Synthesis of novel analogs of 2-pyrazoline obtained from [(7-chloroquinolin-4-yl)amino]chalcones and hydrazine as potential antitumor and antimalarial agents. Eur. J. Med. Chem. 2013, 67, 252-262.

18. Rathore, P.; Yaseen, S.; Ovais, S.; Bashir, R.; Yaseen, R.; Hameed, A.D.; Samim, M.; Gupta, R.; Hussain, F.; Javed, K. Synthesis and evaluation of some new pyrazoline substituted benzenesulfonylureas as potential antiproliferative agents. Bioorg. Med. Chem. Lett. 2014, 24, 1685-1691.

19. Lv, P.-C.; Li, D.-D.; Li, Q.-S.; Lu, X.; Xiao, Z.-P.; Zhu, H.-L. Synthesis, molecular docking and evaluation of thiazolyl-pyrazoline derivatives as EGFR TK inhibitors and potential anticancer agents. Bioorg. Med. Chem. Lett. 2011, 21, 5374-5377.

20. Shin, S.Y.; Yoon, H.; Hwang, D.; Ahn, S.; Kim, D.-W.; Koh, D.; Lee, Y.H.; Lim, Y. Benzochalcones bearing pyrazoline moieties show anti-colorectal cancer activities and selective inhibitory effects on aurora kinases. Bioorg. Med. Chem. 2013, 21, 7018-7024.

21. Yu, M.; Yang, H.; Wu, K.; Ji, Y.; Ju, L.; Lu, X. Novel pyrazoline derivatives as bi-inhibitor of COX-2 and B-Raf in treating cervical carcinoma. Bioorg. Med. Chem. 2014, 22, 4109-4118.

22. Amin, K.M.; Abou-Seri, S.M.; Awadallah, F.M.; Eissa, A.A.M.; Hassan, G.S.; Abdulla, M.M. Synthesis and anticancer activity of some 8-substituted-7-methoxy-2H-chromen-2-one derivatives toward hepatocellular carcinoma HepG2 cells. Eur. J. Med. Chem. 2015, 90, 221-231.

23. Qin, Y.-J.; Li, Y.-J.; Jiang, A.-Q.; Yang, M.-R.; Zhu, Q.-Z.; Dong, H.; Zhu, H.-L. Design, synthesis and biological evaluation of novel pyrazoline-containing derivatives as potential tubulin assembling inhibitors. Eur. J. Med. Chem. 2015, 94, 447-457.

24. De Oliveira, C.S.; Lira, B.F.; Barbosa-Filho, J.M.; Lorenzo, J.G.F.; de Athayde-Filho, P.F. Synthetic Approaches and Pharmacological Activity of 1,3,4-Oxadiazoles: A Review of the Literature from 2000-2012. Molecules 2012, 17, 10192-10231.

25. Khan, I.; Ibrar, A.; Abbas, N. Oxadiazoles as Privileged Motifs for Promising Anticancer Leads: Recent Advances and Future Prospects. Arch. Pharm. Chem. Life Sci. 2014, 347, doi:10.1002/ardp.201300231.

26. Bajaj, S.; Asati, V.; Singh, J.; Roy, P.P. 1,3,4-Oxadiazoles: An emerging scaffold to target growth factors, enzymes and kinases as anticancer agents. Eur. J. Med. Chem. 2015, 97, 124-141.

27. Küçükgüzel, Ş.G.; Çıkla-Süzgün, P. Recent advances bioactive 1,2,4-triazole-3-thiones. Eur. J. Med. Chem. 2015, 97, 830-870.

28. Kumar, C.N.S.S.P.; Parida, D.K.; Santhoshi, A.; Kota, A.K.; Sridhar, B.; Rao, V.J. Synthesis and biological evaluation of tetrazole containing compounds as possible anticancer agents. Med. Chem. Commun. 2011, 2, 486-492.

29. Haider, S.; Alam, M.S.; Hamid, H. 1,3,4-Thiadiazoles: A potent multi targeted pharmacological scaffold. Eur. J. Med. Chem. 2015, 92, 156-177.

30. Kaplancıkl1, Z.A.; Özdemir, A.; Turan-Zitouni, G.; Altintop, M.D.; Can, Ö.D. New pyrazoline derivatives and their antidepressant activity. Eur. J. Med. Chem. 2010, 45, 4383-4387. 
31. Altintop, M.D.; Özdemir, A.; Kaplancikli, Z.A.; Turan-Zitouni, G.; Temel, H.E.; Çiftçi Gülşen, A. Synthesis and Biological Evaluation of Some Pyrazoline Derivatives Bearing a Dithiocarbamate Moiety as New Cholinesterase Inhibitors. Arch. Pharm. Chem. Life Sci. 2013, 346, 189-199.

32. Özdemir, A.; Altintop, M.D.; Kaplancıkl1, Z.A.; Turan-Zitouni, G.; Karaca, H.; Tunal1, Y. Synthesis and Biological Evaluation of Pyrazoline Derivatives Bearing an Indole Moiety as New Antimicrobial Agents. Arch. Pharm. Chem. Life Sci. 2013, 346, 463-469.

33. Özdemir, A.; Altıntop, M.D.; Kaplancıklı, Z.A.; Turan-Zitouni, G.; Çiftçi, G.A.; Ulusoylar Yıldırım, Ş. Synthesis of 1-acetyl-3-(2-thienyl)-5-aryl-2-pyrazoline derivatives and evaluation of their anticancer activity. J. Enzyme Inhib. Med. Chem. 2013, 28, 1221-1227.

34. Altıntop, M.D.; Özdemir, A.; Turan-Zitouni, G.; Ilgın, S.; Atlı, Ö.; Demirel, R.; Kaplancıklı, Z.A. A novel series of thiazolyl-pyrazoline derivatives: Synthesis and evaluation of antifungal activity, cytotoxicity and genotoxicity. Eur. J. Med. Chem. 2015, 92, 342-352.

35. Özdemir, A.; Altıntop, M.D.; Kaplancıklı, Z.A.; Can, Ö.D.; Demir-Özkay, Ü.; Turan-Zitouni, G. Synthesis and Evaluation of New 1,5-Diaryl-3-[4-(methylsulfonyl)phenyl]-4,5-dihydro-1H-pyrazole Derivatives as Potential Antidepressant Agents. Molecules 2015, 20, 2668-2684.

36. Turan-Zitouni, G.; Özdemir, A.; Güven, K. Synthesis of some 1-[(N,Ndisubstitutedthiocarbamoylthio)acetyl]-3-(2-thienyl)-5-aryl-2-pyrazoline derivatives and investigation of their antibacterial and antifungal activities, Arch. Pharm. Chem. Life Sci. 2005, 338, 96-104.

37. Özdemir, A.; Turan-Zitouni, G.; Kaplancıklı, Z.A.; Revial, G.; Demirci, F.; İşcan, G. Preparation of some pyrazoline derivatives and evaluation of their antifungal activities. J. Enzyme Inhib. Med. Chem. 2010, 25, 565-571.

38. Mossman, T. Rapid calorimetric assay for cellular growth and survival: Application to proliferation and cytotoxic assays. J. Immunol. Methods 1983, 65, 55-63.

39. Boersma, A.; Nooter, K; Oostrum, R.; Stoter, G. Quantification of apoptotic cells with fluorescein isothiocyanate-labeled annexin $\mathrm{V}$ in Chinese hamster ovary cell cultures treated with cisplatin. Cytometry 1996, 24, 123-130.

40. Martin, S.; Reutelingsperger, C.; Mcgahon, A.; Rader, J.; Vanschie, R.; Laface, D.; Green, D. Early redistribution of plasma-membrane phosphatidylserine is a general feature of apoptosis regardless of the initiating stimulus-Inhibition by overexpression of bcl-2 and abl. J. Exp. Med. 1995, 182, $1545-1556$.

Sample Availability: Samples of the compounds 1-12 are available from the authors.

(C) 2015 by the authors; licensee MDPI, Basel, Switzerland. This article is an open access article distributed under the terms and conditions of the Creative Commons Attribution license (http://creativecommons.org/licenses/by/4.0/). 